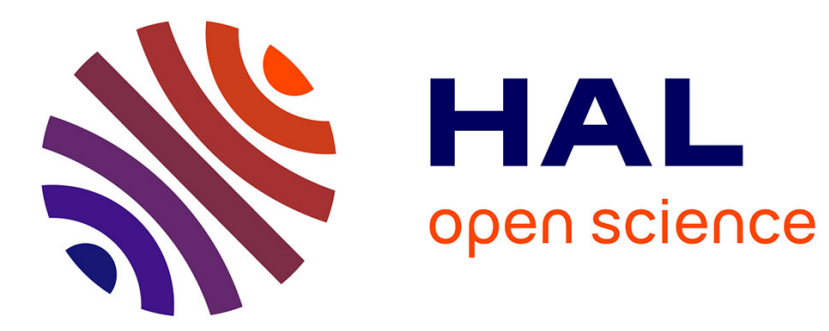

\title{
Modelling evaporation processes in soils from the Huasco salt flat basin, Chile
}

\author{
M.F. Hernandez Lopez, Isabelle Braud, J. Gironas, F. Suarez, J.F. Munoz
}

\section{To cite this version:}

M.F. Hernandez Lopez, Isabelle Braud, J. Gironas, F. Suarez, J.F. Munoz. Modelling evaporation processes in soils from the Huasco salt flat basin, Chile. Hydrological Processes, 2016, 30 (25), pp.47044719. 10.1002/hyp.10987. hal-01743221

\section{HAL Id: hal-01743221 \\ https://hal.science/hal-01743221}

Submitted on 26 Mar 2018

HAL is a multi-disciplinary open access archive for the deposit and dissemination of scientific research documents, whether they are published or not. The documents may come from teaching and research institutions in France or abroad, or from public or private research centers.
L'archive ouverte pluridisciplinaire HAL, est destinée au dépôt et à la diffusion de documents scientifiques de niveau recherche, publiés ou non, émanant des établissements d'enseignement et de recherche français ou étrangers, des laboratoires publics ou privés. 
1 Modeling evaporation processes in soils from the Huasco salt flat basin, Chile

3 María Fernanda Hernández-López ${ }^{1,2}$, Isabelle Braud ${ }^{3}$ Jorge Gironás $^{2,4,5}$, Francisco

4 Suárez $^{2,4, *}$, José Francisco Muñoz ${ }^{2}$

$11{ }^{1}$ AMEC, Environment \& Infrastructure, Av. Apoquindo 3846 / Las Condes, Santiago, Chile.

$12{ }^{2}$ Departamento de Ingeniería Hidráulica y Ambiental, Pontificia Universidad Católica de Chile,

13 Av. Vicuña Mackenna 4860, Santiago, Chile. Casilla 306, Correo 22, Santiago, Chile.

$14{ }^{3}$ Irstea, UR HHLY, 5 Rue de la Doua, CS 70077, 69626 Villeurbanne Cedex, France.

154 Centro de Desarrollo Urbano Sustentable (CEDEUS), CONICYT/FONDAP/15110020,

16 Santiago, RM, Chile.

$17{ }^{5}$ Centro de Investigación para la Gestión Integrada de Desastres Naturales (CIGIDEN),

18 CONICYT/FONDAP/15110017, Santiago, RM, Chile.

19

$20 *$ Corresponding author: fsuarez@ing.puc.cl. 


\section{ABSTRACT}

The need to understand and simulate hydrological phenomena and their interactions, and the

25 impact of anthropogenic and climate changes on natural environments have promoted the study of 26 evaporation from bare soils in arid climates. In closed Altiplano basins, such as those encountered in arid

27 and hyper arid basins in northern Chile, evaporation from shallow groundwater is the main source of 28 aquifer depletion and thus, its study is crucial for water resources management. The objective of this work 29 is to understand the mechanisms of evaporation in saline soils with shallow water tables, in order to better 30 quantify evaporation fluxes and improve our understanding of the water balance in these regions. To 31 achieve this objective, a model that couples fluid flow with heat transfer was developed and calibrated 32 using column experiments with saline soils from the Huasco salt flat basin, Chile. The model enables 33 determination of both liquid and water vapor fluxes, as well as the location of the evaporation front.

34 Experimental results showed that salt transport inside the soil profile modified the water retention curve,

35 highlighting the importance of including salt transport when modeling the evaporation processes in these 36 soils. Indeed, model simulations only agreed with the experimental data when the effect of salt transport 37 on water retention curves was taken into account. Model results also showed that the evaporation front is 38 closer to the soil surface as the water table depth reduces. Therefore, the model allows determining the 39 groundwater level depth that results in disconnection of liquid fluxes in the vadose zone. A sensitivity 40 analysis allowed understanding the effect of water-flux enhancements mechanisms on soil evaporation.

41 The results presented in this study are important as they allow quantifying the evaporation that occurs in 42 bare soils from Altiplano basins, which is typically the main water discharge in these closed basins.

43 Keywords: Soil evaporation, Altiplano basins, saline soil column, vapor flow, SiSPAT 


\section{Introduction}

The need to understand and simulate hydrological phenomena and their interactions, and

47 the impact of anthropogenic and climate changes on natural environments have promoted the

48 study of evaporation from bare soils in arid climates (Alazard et al., 2015). However, current

49 knowledge of evaporation remains incomplete because the complex and strongly coupled

50 interaction of transport mechanisms (phase change, capillary flow, film flow, vapor diffusion),

51 soil properties (hydrodynamic and thermal), and atmospheric forcings (air temperature, relative

52 humidity, radiation, atmospheric stability) are not well understood (Trautz et al., 2015). In closed

53 Altiplano basins such as those encountered in arid and hyper arid basins in the northern Chile,

54 evaporation is the main source of aquifer depletion, and thus its study is crucial for water

55 resources management. Understanding evaporation is also important for the study of sensitive

56 soil systems such as wetlands (de la Fuente and Niño, 2010; Johnson et al., 2010). Nonetheless,

57 understanding the evaporation processes in these environments is complex because evaporation

58 occurs under non-isothermal conditions, where water can be mobilized as liquid water or water

59 vapor (Nassar and Horton, 1989; Grifoll et al., 2005; Hernández-López, 2014). In addition,

60 quantifying evaporation in Altiplano basins is difficult due to the harsh conditions, the spatial

61 variability of the evaporation rates, and also due to the difficulty in accessing this region (Kampf

62 et al., 2005; Johnson et al., 2010).

Many studies have been carried out using laboratory soil columns to improve the

64 knowledge on the evaporation mechanisms, focusing on the combined transport of water, heat

65 and solutes (Nassar and Horton, 1989; Cahill and Parlange, 1998; Konukcu et al., 2004; Braud et 
66 al., 2005b; 2009a; Gran et al., 2011; Nachshon et al., 2011; Schulz et al., 2015). These studies

67 have been performed in homogeneous soils of sand or silt under saturated conditions at the 68 beginning of the experiments, and have used saline solutions or deionized water. These 69 investigations have enabled the calibration and validation of numerical models to solve the 70 coupled equations of liquid water, water vapor, heat and solute flows, which can be used as

71 predictive tools to quantify evaporation fluxes in arid regions (Boulet et al., 1997; Grifoll et al., 72 2005; Braud et al., 2009b; Saito et al., 2006; Novak, 2010). Nonetheless, few studies have tried to 73 understand the evaporation processes in a homogeneous natural saline medium from Altiplano 74 basins (Johnson et al., 2010; Hernández-López et al., 2014). Moreover, Lictevout et al. (2013), 75 who performed an extensive assessment of the water resources in the north of Chile, highlights 76 that the main problem in the Altiplanic closed basins is the lack of evaporation data. Although 77 studies that involve field data collection have been carried out in these regions, e.g., see Johnson 78 et al. (2010), numerical modelling has not been used to quantify the different evaporation 79 processes that occur in the soils from these environments. In a recent study, Hernández-López et 80 al. (2014) measured the temporal and spatial evolution of soil water content, electrical 81 conductivity and temperature under different groundwater levels in a laboratory column filled 82 with natural saline soil from the Huasco salt flats basin, Chile. They estimated the thermal and 83 isothermal liquid and vapor fluxes and tried to determine the location of the evaporation front, 84 which could not be precisely determined due to their sensors' poor spatial resolution. 85 Nonetheless, these experiments provided a valuable data set that can be used to better understand 86 evaporation processes in saline soils with shallow water tables using numerical modelling. 
The objective of this work is to complement the measurements performed by Hernández-

88 López et al. (2014) by conducting a modeling study that can improve the understanding of

89 evaporation processes from bare soils in the Chilean Altiplano basins. The specific objectives of

90 this study are to: (1) develop and calibrate a numerical model that can represent the soil water

91 content and thermal profiles, as well as the evaporation fluxes; (2) simulate liquid water and

92 water vapor fluxes to locate the evaporation front; and (3) perform a sensitivity analysis on the

93 calibrated parameters to ensure their validity based on physical constrains. To achieve these

94 objectives, we used the bare soil version of the SiSPAT (Simple Soil Plant Atmosphere Transfer)

95 model (Braud et al., 1995) and optimized the soil hydrodynamic and thermal properties to

96 adequately represent the experiments reported by Hernández-López et al. (2014). Different water

97 fluxes were analyzed in detail using the optimized model results for two water table levels, and

98 the location of the evaporation front was found. A sensitivity analysis was carried out to better

99 understand the uncertainty that calibration parameters (e.g., tortuosity, enhancement factor) have

100 on evaporation, and finally a discussion of the limitations of our approach is presented.

\section{$101 \quad 2$ Materials and Methods}

\section{$102 \quad 2.1$ Soil hydraulic properties}

103 In this study, we utilized the soil collected by Hernández-López et al. (2014) from the

104 Huasco salt flat basin, Chile. This soil had 95\% sand, 4\% silt, 1\% clay, an in-situ dry bulk density

105 of $1.55 \mathrm{~g} \mathrm{~cm}^{-3}$, and a soil bulk electrical conductivity of $8.1 \mathrm{dS} \mathrm{m}^{-1}$ (measured at a soil water

106 content of $\sim 0.07 \mathrm{~m}^{3} \mathrm{~m}^{-3}$ ). The soil's water retention curve was obtained experimentally using a 5-

107 bar pressure plate extractor (1660, Soilmoisture Equipment Corp., Santa Barbara, CA). The van 
108 Genuchten model (1980) was fitted to the experimental measurements to estimate the parameters

109 of the water retention curve:

$110 \quad \theta(h)=\theta_{r}+\frac{\theta_{s}-\theta_{r}}{\left[1+(\alpha h)^{n}\right]^{m}}$

111 where $\theta\left(\mathrm{m}^{3} \mathrm{~m}^{-3}\right)$ is the volumetric water content; $\theta_{r}$ and $\theta_{s}\left(\mathrm{~m}^{3} \mathrm{~m}^{-3}\right)$ are the residual and

112 saturated water contents, respectively; $\alpha\left(\mathrm{m}^{-1}\right)$ is the inverse of the air-entry pressure; $h(\mathrm{~m})$ is the 113 soil water suction or negative pressure expressed as an equivalent water column; and $n$ and $m(-)$

114 are empirical parameters. In the following, we use the Mualem hypothesis (i.e., $\mathrm{m}=1-1 / \mathrm{n}$ ).

115 The saturated hydraulic conductivity, $K_{s}\left(\mathrm{~m} \mathrm{~s}^{-1}\right)$, was measured using a constant head 116 permeameter (Soil Measurement System, Tucson, AZ), and the unsaturated hydraulic 117 conductivity was determined using the Brooks-Corey-Burdine model (Brooks and Corey, 1964):

$118 K(\theta)=K_{S}\left(\frac{\theta}{\theta_{S}}\right)^{\beta}$

119 where $K(\theta)\left(\mathrm{m} \mathrm{s}^{-1}\right)$ is the hydraulic conductivity at a volumetric water content of $\theta$, and $\beta(-)$ is an 120 empirical coefficient.

\section{$121 \quad 2.2$ Evaporation experiments}

122 Quasi steady state soil evaporation experiments were conducted in a laboratory with

123 controlled environmental conditions (ambient temperature of $22 \pm 2.5^{\circ} \mathrm{C}$ and relative humidity

124 between $25 \%$ and $58 \%$ ). An unaltered dry soil sample collected from the Huasco salt flat basin 125 was transported in layers to the laboratory and packed homogeneously in an insulated acrylic 
126 column of $0.35 \mathrm{~m}$ internal diameter and $1.20 \mathrm{~m}$ height. The packing reproduced the in-situ dry

127 bulk density.

The bottom of the soil column was connected to an external reservoir, which fixed the

129 water table level within the column. Temperature $(T)$ was measured in the soil profile using

130 thermistors (107-L, Campbell Sci., Logan, UT). Soil water content $(\theta)$ and electrical conductivity

$131(\sigma)$ were measured using time domain reflectometry (TDR) probes (CS645, Campbell Sci.,

132 Logan, UT). The accuracy and precision in the measurement of the soil water content were $0.5 \%$

133 and $0.05 \%$, respectively. The accuracy in the electrical conductivity measurements was $\sim 1 \%$.

134 Temperature and TDR probes were installed at nine depths in the soil profile spaced equally

135 between 5 and $45 \mathrm{~cm}$ depth (measured from the soil surface). These data were collected using a

136 datalogger (CR1000, Campbell Sci., Logan, UT).

In the first experiment, the external reservoir fixed the water level at $0.75 \mathrm{~m}$ (below the

138 soil surface). The evaporation experiments were carried out using tap water and thus the source

139 of salinity was the soil itself. Evaporation was driven by an infrared lamp (General Electric IR

$140150 \mathrm{~W}$ ) located $0.30 \mathrm{~m}$ above the soil surface and enhanced using a fan that simulated wind

141 speeds of $0.2 \mathrm{~m} \mathrm{~s}^{-1}$. The infrared lamp was on from 8:00 to 18:00 hours to simulate the diurnal

142 cycle of solar radiation. Air temperature and relative humidity measurements were recorded in

143 the laboratory and at the surface of the column with two shielded sensors (HMP75, Vaisala,

144 Helsinki, Finland) at 15-min intervals. Daily evaporation rates were estimated with a precision of

$1450.7 \mathrm{~mm} \mathrm{day}^{-1}$ from the water level fluctuations in the external reservoir. The profiles of $T, \theta$, and

$146 \sigma$ were monitored at 5-min intervals, and the evaporated water was replenished daily in the 
147 external reservoir to maintain a fixed water level. When the previous variables varied in less than

$1481 \%$, it was assumed that steady state was reached (typically after $\sim 20$ days). This state was used

149 to model the evaporation process within the soil column (described below). Then, the water level

150 was raised to a depth of $0.40 \mathrm{~m}$ and the experiment was repeated. More details about these

151 experiments are presented in Hernández-López et al. (2014), in which evaporation rates vs. water

152 table depth observations in the laboratory are successfully compared to lysimeters and in-situ

153 chamber measurements in the Huasco salt flat basin.

\section{$154 \quad 2.3$ Description of the numerical model}

\section{$155 \quad$ 2.3.1 Water flow and heat transport equations}

156 To represent the hydrodynamics in the evaporation experiments, we adapted the SiSPAT

157 model (Braud et al., 1995) to the laboratory conditions. SiSPAT simulates the one-dimensional

158 heat and water transfer in the soil-plant-atmosphere system by coupling the liquid and water

159 vapor flow equations based on the approach of Philip and de Vries (1957), modified by Milly

160 (1984). The modified SiSPAT model is divided into three modules: soil, atmosphere, and soil-

161 atmosphere interface. In the soil module, water flow and heat transport are described as a coupled

162 system of two mass and heat transfer equations that predict temperature and soil water suction 163 fields:

$164 \quad C_{h} \frac{\partial h}{\partial t}=\frac{\partial}{\partial z}\left(D_{m h} \frac{\partial h}{\partial z}+D_{m T} \frac{\partial T}{\partial z}-K(h)\right)$

$165 C_{T} \frac{\partial T}{\partial t}=\frac{\partial}{\partial z}\left(D_{c h} \frac{\partial h}{\partial z}+\lambda \frac{\partial T}{\partial z}\right)$ 
166 where $T$ is the soil temperature $(\mathrm{K}), C_{h}\left(\mathrm{~m}^{-1}\right)$ and $C_{T}\left(\mathrm{~J} \mathrm{~m}^{-3} \mathrm{~K}^{-1}\right)$ are the capillary capacity and

167 volumetric heat capacity, respectively; $t(\mathrm{~s})$ is time; and $z(\mathrm{~m})$ is the spatial coordinate oriented 168 downward. The transport coefficients are the isothermal hydraulic conductivity $169 D_{m h}=K+D_{v h} / \rho_{w}\left(\mathrm{~m} \mathrm{~s}^{-1}\right)$, the thermal vapor hydraulic conductivity $D_{m T}=D_{v T} / \rho_{w}\left(\mathrm{~m}^{2} \mathrm{~K}^{-1} \mathrm{~s}^{-}\right.$

$170^{1}$ ), the isothermal vapor hydraulic conductivity $D_{c h}=L_{v} D_{v h}\left(\mathrm{~m} \mathrm{~s}^{-1}\right)$, and the apparent thermal

171 conductivity $\lambda\left(\mathrm{W} \mathrm{m}^{-1} \mathrm{~K}^{-1}\right) . K(h)\left(\mathrm{m} \mathrm{s}^{-1}\right)$ is the unsaturated hydraulic conductivity of the liquid

172 phase as a function of water suction, $D_{v h}\left(\mathrm{~m}^{2} \mathrm{~s}^{-1}\right)$ is the isothermal vapor diffusivity, $D_{v T}\left(\mathrm{~m}^{2} \mathrm{~s}^{-1}\right)$

173 is the thermal vapor diffusivity, $\rho_{w}\left(\mathrm{~kg} \mathrm{~m}^{-3}\right)$ is the water density, and $L_{v}\left(\mathrm{~J} \mathrm{~kg}^{-1}\right)$ is the latent heat

174 of vaporization. All these coefficients can be expressed as function of soil water content and/or 175 temperature, as shown in Table 1 . Note that $D_{v h}$ and $D_{v T}$ are function of the tortuosity factor, $\tau_{a}$, 176 and the enhancement factor, $\eta$, respectively, as shown in Table 1 . The description of the 177 tortuosity and enhancement factors is provided with more details in section 2.4.

\subsubsection{Model parameters and initial and boundary conditions}

In the model, the soil column was first discretized using only one horizon and a variable

180 grid spacing with a finer resolution close to the top and bottom interfaces (minimum and

181 maximum layer thickness of 0.001 and $0.005-\mathrm{m}$ respectively) to simulate a vertically

182 homogeneous soil. Then, different horizons were adopted to simulate spatial heterogeneity

183 (described below). This approach required considering variable thicknesses with finer resolutions

184 close to the interfaces between horizons. In this last case, the minimum and maximum layer

185 thicknesses were $0.001 \mathrm{~m}$ and $0.005 \mathrm{~m}$ respectively. Table 2 presents the model parameters, and 186 the chosen initial and boundary conditions used to represent the evaporation experiments for the 
187 homogeneous soil case. For water flow, the experimental soil hydraulic properties (i.e., water

188 retention curve and saturated hydraulic conductivity) were considered as the initial parameters

189 set. For heat transport, the parameters of the apparent thermal conductivity, described using the

190 Laurent and Guerre-Chaley model (Laurent and Guerre-Chaley, 1995) were used. Then, to

191 improve model predictions, these parameters were calibrated as described later. condition, a known water flux equal to the evaporation flux at the surface was used. On the other hand, constant average daily temperatures of 11.42 and $13.90^{\circ} \mathrm{C}$, which were imposed for the $0.75 \mathrm{~m}$ and $0.40 \mathrm{~m}$ water table levels, respectively, were used as the bottom boundary condition for heat transport. The choice of the water transfer bottom boundary condition is consistent with

198 the experimental conditions, where the soil column was replenished daily from the bottom to 199 compensate for surface evaporation. Another type of boundary condition, where a constant 200 pressure (i.e. the water table depth) is imposed at the bottom of the domain, was also tested and is 201 discussed in the sensitivity analysis discussed in section 4.2. Also, note that the temperatures at 202 the bottom for the 0.75 and $0.40 \mathrm{~m}$ water table levels are different because even when the 203 experiments were conducted successively, they were carried out at different times of the year.

204 The temperature values correspond to an extrapolation of the data measured at $50 \mathrm{~cm} \mathrm{depth}$. The 205 upper boundary condition was adapted to the laboratory experimental conditions since it was not 206 possible to compute the surface energy balance as required by SiSPAT. In the upper boundary, 207 surface temperature, relative humidity and wind speed measurements were used to calculate the 208 evaporation flux (Braud et al., 2009b). These measurements were included in the model as 
209 follows: air temperature $T_{a}(\mathrm{~K})$ and relative humidity $H_{r}(-)$ were measured at a reference level $z_{a t}$

$210=0.01 \mathrm{~m}$, and the wind speed $U_{a}\left(\mathrm{~m} \mathrm{~s}^{-1}\right)$ at a reference level $z_{a v}=0.3 \mathrm{~m}$. Bare soil evaporation, $E$

$211\left(\mathrm{~m} \mathrm{~s}^{-1}\right)$, was calculated using the following equation:

$212 E=\rho_{a} \frac{\left(q_{s}-q_{a}\right)}{R_{a H}}$

213 where $\rho_{a}\left(\mathrm{~kg} \mathrm{~m}^{-3}\right)$ is the air density, $R_{a H}\left(\mathrm{~s} \mathrm{~m}^{-1}\right)$ is the aerodynamic resistance to heat and water

214 vapor transfer, and $q_{s}(-)$ and $q_{a}(-)$ are the soil and air surface specific humidity, respectively. $q_{s}$

215 and $q_{a}$ are related to the soil surface temperature $T_{s}(\mathrm{~K})$, the air temperature $T_{a}(\mathrm{~K})$, and the

216 relative humidity of the soil $H_{r s}(-)$ and the air $H_{a}(-)$ by:

$217 \quad q_{s}=\frac{0.622 e_{s a t}\left(T_{s}\right) H_{r s}}{P_{a t m}-0.378 e_{s a t}\left(T_{s}\right) H_{r s}}$

$218 \quad q_{a}=\frac{0.622 e_{s a t}\left(T_{a}\right) H_{a}}{P_{a t m}-0.378 e_{s a t}\left(T_{a}\right) H_{a}}$

$219 \quad H_{r s}=\exp \left(\frac{M g h}{R T_{a}}\right)$

220 where $P_{\text {atm }}(\mathrm{Pa})$ is the atmospheric pressure, $R\left(\mathrm{~J} \mathrm{~mol}^{-1} \mathrm{~K}^{-1}\right)$ is the gas constant, $M\left(\mathrm{~kg} \mathrm{~mol}^{-1}\right)$ is the

221 molecular weight of water and $e_{s a t}(T)$ is the saturated vapor pressure at a temperature $T$. The

222 value of $q_{s}$ at the soil surface $(z=0)$ was computed using the simulated values of soil temperature

223 and soil water pressure in Eqs. (6) and (8).

al., 2000): 


$$
\begin{array}{ll}
R_{a H}=R_{a o}(1+S t a b)^{-2} & \text { Stab } \leq 0 \\
R_{a H}=R_{a o}(1+S t a b)^{-0.75} & \text { Stab } \geq 0
\end{array}
$$

where Stab (-) is a stability parameter and $R_{a o}\left(\mathrm{~s} \mathrm{~m}^{-1}\right)$ is the aerodynamic resistance under neutral

$230 \quad S t a b=\frac{5 g z_{a t}\left(T_{s}-T_{a}\right)}{T_{a} U_{a}^{2}}$

Finally, the aerodynamic resistance under neutral conditions is defined as (Shuttleworth

$233 \quad R_{a o}=\frac{1}{k^{2} U_{a}}\left[\ln \left(\frac{z_{a t}}{z_{o m}}\right)\right]^{2}$

234 where $z_{\text {om }}(\mathrm{m})$ is the roughness length for momentum, and $k \approx 0.4(-)$ is the von Karman constant.

\subsubsection{Calibration procedure and calibration metrics}

As described before, the experimental soil hydraulic properties were used as the initial parameters set to run the model. As the soil was packed homogeneously in the soil column, these

238 properties were assumed to be uniform within the soil profile. Then, these properties were

239 adjusted to fit the modeled results to the evaporation experiments observations. The model

240 parameters were fitted manually, based on the comparison of modeled and observed soil

241 volumetric water content and temperature profiles. Once the parameters were fitted, the 242 cumulative evaporation simulated at the soil surface was compared to the experimental 
243 cumulative evaporation. The calibration metrics used to quantify the goodness of fit were the root

244 mean square error $(R M S E)$, the bias $(B)$, and the Nash-Sutcliffe efficiency $(E)$ :

$245 \quad R M S E=\sqrt{\frac{1}{n}\left(y_{i}^{\bmod }-y_{i}^{o b s}\right)^{2}}$

$246 \quad B=\frac{1}{n} \sum_{i=1}^{i=n}\left(y_{i}^{\bmod }-y_{i}^{o b s}\right)$

$E=1-\frac{\sum_{i=1}^{i=n}\left(y_{i}^{\bmod }-y_{i}^{o b s}\right)^{2}}{\sum_{i=1}^{i=n}\left(\bar{y}^{o b s}-y_{i}^{o b s}\right)^{2}}$

248 where $y_{i}^{\text {mod }}$ are the modeled values, $y_{i}^{o b s}$ the corresponding observed values, and $y^{o b s}$ is the

249 average value of all observed data. These statistics were computed using the observed profiles of

250 temperature and soil water content at the end of the experiment and the modelled values at the

251 same depths.

\section{$252 \quad 2.4$ Sensitivity analysis}

253 A sensitivity analysis can provide valuable information about the evaporation mechanisms

254 and the role of various parameters on these mechanisms. In our sensitivity analysis, the impact of

255 the variation of different parameters on cumulative evaporation was assessed. Although the

256 processes involved in evaporation are strongly coupled, we focused the sensitivity analysis on

257 two parameters of the vapor flow component: tortuosity $\left(\tau_{a}\right)$ and the enhancement factor $(\eta)$,

258 which are the most uncertain parameters in the isothermal and thermal water vapour fluxes respectively. 
261 values less than 1.0 (Penman, 1940; Millington and Quirk, 1961; Abu-El-Sha'r and Abriola, 262 1997). In the sensitivity analysis, we considered several constant tortuosity values in the soil

263 profile, ranging between 0.1 and 0.3 ; and the expression of the tortuosity factor proposed by

264 Millington and Quirk (1961), as reported by Saito et al. (2006):

$265 \tau_{a}=\frac{a_{v}^{7 / 3}}{\theta_{s}^{2}}=\frac{\left(\theta_{s}-\theta\right)^{7 / 3}}{\theta_{s}^{2}}$

266 where $a_{v}\left(\mathrm{~m}^{3} \mathrm{~m}^{-3}\right)$ is the air content.

$$
\eta=a+3 \frac{\theta}{\theta_{S}}-(a-1) \exp \left\{-\left[\left(1+\frac{2.6}{\sqrt{f_{C}}}\right) \frac{\theta}{\theta_{S}}\right]^{3}\right\}
$$

271 where $f_{c}$ is the clay fraction of the soil studied and $a$ is an adjustment factor that was varied

272 between 3.0 and 9.5. Note that the reference simulation discussed in section 3.2 was performed 273 using $\eta=1.5$ and the tortuosity given by Eq. (15).

\section{Results}


278 profiles, for the 0.75 and $0.40 \mathrm{~m}$ water table levels. The modeled results were obtained assuming

279 a soil profile that has vertically uniform hydraulic properties. Figure 1 also shows the

280 corresponding observed electrical conductivity $(\sigma)$ profiles. The experimental and modeled

281 results depicted in Figure 1 correspond to the mean daily values after 20 days of fixing the water

282 table level. The soil column experiments began with a dry soil and then the water table was fixed

283 at a depth of $0.75 \mathrm{~m}$. After 20 days, the electrical conductivity profile showed a zone of

284 increased conductivity ( 0.2-0.3 $\mathrm{m}$ depth) that is correlated to a zone of increased moisture 285 content.

The simulation results presented in Figure 1 highlights the inability of the numerical model to correctly represent the hydraulic and thermal behavior assuming a vertically

288 homogeneous soil and using the soil hydraulic properties obtained from independent laboratory 289 experiments. From Figure 1 it is clear that using spatially uniform soil's hydrodynamic properties 290 in the modeling exercise does not allow a correct simulation of the experimental soil moisture 291 and thermal profiles for both water table levels. Additional sensitivity analyses showed that it is 292 not possible to reproduce the observed profiles when the hydrodynamic properties are considered 293 uniform along the soil profile (data not shown).

Figure 2 shows the mean observed and modeled soil water content and temperature 295 profiles on day 20 for the 0.75 and $0.40 \mathrm{~m}$ water table levels, when using the optimized 296 parameters for each horizon in the soil profile. For the $0.75 \mathrm{~m}$ water table level, the thicknesses of 297 the soil horizons were: $0.20 \mathrm{~m}$ for horizon $1(\mathrm{H} 1)$; $0.10 \mathrm{~m}$ for horizon $2(\mathrm{H} 2)$; and $0.90 \mathrm{~m}$ for 
298 horizon 3 (H3). For the $0.40 \mathrm{~m}$ water table level, the thicknesses of the soil horizons were: $0.15 \mathrm{~m}$

299 for $\mathrm{H} 1 ; 0.15 \mathrm{~m}$ for $\mathrm{H} 2$; and $0.90 \mathrm{~m}$ for $\mathrm{H} 3$. These thicknesses were determined according to the 300 experimental results presented by Hernández-López et al. (2014). Table 3 presents the values of 301 the parameters obtained in the calibration process. After calibrating the soil hydraulic and thermal 302 properties, the model results agree fairly well with the experimental data and suggest that the 303 only way to represent water and heat transport in these experiments is by accounting for the soil 304 properties spatial variability, which are likely to be modified as a consequence of salt transport 305 and precipitation/dissolution reactions (Vásquez et al., 2013; Fierro, 2015; Nachshon and 306 Weisbrod, 2015).

Table 4 presents the calibration metrics obtained after considering the three soil horizons

308 and the experimental and modeled cumulative evaporation values, for both the 0.75 and of 0.40

$309 \mathrm{~m}$ water table levels. The values of the $R M S E, B$, and $E$ for soil water content and temperature are

310 very good for the $0.75 \mathrm{~m}$ water table depth and lower for the $0.4 \mathrm{~m}$ water table depth. The

311 calibrated model correctly reproduces the observed evaporation values from the laboratory

312 measurements, with differences of $\sim 0.01 \mathrm{~mm}$ in the cumulative evaporation for the $0.75 \mathrm{~m}$ water

313 table depth and $\sim 0.67 \mathrm{~mm}$ for the $0.40 \mathrm{~m}$ water table depth. Also, by simultaneously reproducing

314 the soil water content and the thermal profiles, and the cumulative evaporation, the problem of 315 equifinality is minimized (Tang and Zhuang, 2008) (this is discussed in more details in the 316 sensitivity analysis). These results highlight the importance of calibrating the model parameters 317 for each water table level in order to obtain a better estimate of the main mechanism that govern 318 the evaporation fluxes. 
321 The evaporation fluxes are related to vapor transfer due to temperature and pressure 322 gradients (Boulet et al., 1997). Figures 3 (a) and (b) show the total water flux, $q_{T}$, the liquid water 323 flux, $q_{L}$, and water vapor flux, $q_{v}$, profiles for the 0.75 and $0.40 \mathrm{~m}$ water table depths, 324 respectively. Figures 3 (c) and (d) present the vapor fluxes due to thermal $\left(q_{v T}\right)$ and pressure $\left(q_{v h}\right)$ 325 gradients for the 0.75 and $0.40 \mathrm{~m}$ water table levels. From these results, three regions can be

326 distinguished in the soil profile: (1) Region 1, located near to the soil surface, between 0 and 0.12 $327 \mathrm{~m}$ for the $0.75 \mathrm{~m}$ water table level and between 0 and $0.03 \mathrm{~m}$ for the $0.40 \mathrm{~m}$ water table level; (2)

328 Region 2, located between 0.12 and $0.41 \mathrm{~m}$ for the $0.75 \mathrm{~m}$ water table level and between 0.03 and $3290.32 \mathrm{~m}$ for the $0.40 \mathrm{~m}$ water table level; and (3) Region 3, located between 0.41 and $0.75 \mathrm{~m}$ for 330 the $0.75 \mathrm{~m}$ water table level, and between 0.32 and $0.40 \mathrm{~m}$ for the $0.40 \mathrm{~m}$ water table level.

331 Our sensitivity analysis focused on determining how the tortuosity $\left(\tau_{a}\right)$ and the 332 enhancement factor $(\eta)$ affect the cumulative evaporation. These parameters were selected for the 333 sensitivity analysis because $\tau_{a}$ is the most uncertain parameter used to determine the isothermal 334 diffusivity $\left(D_{v h}\right)$, and $\eta$ is the parameter with greater uncertainty when calculating the thermal 335 diffusivity $\left(D_{v T}\right)$. Figure 4 presents the results of the sensitivity analysis. On one hand, when $\tau_{a}$ 336 increases, the cumulative evaporation also increases. On the other hand, when $\eta$ increases (i.e., 337 when the $a$ parameter of the Cass et al. (1984) model increases), the cumulative evaporation 338 decreases. 


\section{Discussion}

3404.1 Experimental results, simulations with vertically uniform hydraulic properties, and

\section{calibration of model parameters}

The results of the experiments are discussed in details in Hernandez-Lopez et al. (2014)

343 and here we only present the main findings that are relevant for this modelling study. Because the

344 column was homogeneously packed before the evaporation experiments, the zone of increased

345 electrical conductivity and moisture shown in Figure 1 is likely to be the result of salt movement

346 towards the soil surface as evaporation occurred (Nachshon et al., 2011), and also due to salt

347 transport as the water level rose. We believe that these salt-transport processes resulted in soil

348 stratification (in terms of salt deposition) and soil hydraulic properties that are no more vertically

349 homogeneous. Note also that there was no evidence of spatial heterogeneity across the soil

350 surface or preferential flow along the sidewalls of the soil column. For the $0.4 \mathrm{~m}$ deep water table

351 level, electrical conductivity and soil water content profiles increased at all horizons, as compared

352 to the profiles obtained when the water table was at $0.75 \mathrm{~m}$ depth. This increased water content

353 profile is a consequence of the increased liquid water transport by capillarity. Such a movement

354 was favored in our experimental conditions because we wetted the soil from below as the water

355 table rose. In the zone between $\sim 0.2-0.3 \mathrm{~m}$ depth, this increased water content may also be due to

356 salt accumulation (Scotter, 1974). According to the electrical conductivity profiles, salt

357 crystallized in the smallest pores in the soil as subflorescent precipitation. This crystallization

358 decreases the pore space in the soil matrix and therefore decreases the $K_{s}$ (Nachshon et al., 2011;

359 Vásquez et al., 2013), reduces the vapor flow (Nachshon and Weisbrod, 2015), and also modifies

360 the water retention characteristics (as described below) (Fierro, 2015). Although subflorescent 
361 precipitation has been widely investigated in other disciplines, few investigations have reported

362 this type of precipitation in soils under drying conditions (Weisbrod et al., 2013; Sghaier et al.,

363 2014). To our best knowledge, the present work is the first one reporting probable subflorescence

364 precipitation in laboratory columns designed to study water movement in soils where the water

365 table is rising. Although subflorescence was not directly measured, we rely on electrical

366 conductivity measurements to evidence this phenomenon. More detailed measurements would

367 have been required to clearly show the subflorescence. Moreover, most of the studies that

368 investigate salt precipitation in soils have been performed with initially saturated soil columns

369 where efflorescent precipitation or formation of a salt crust was observed at the surface of the

370 column when the water table was lowered (Gran et al., 2011; Nachshon et al., 2011). salt transport and a probable salt accumulation within the soil column (Hernández-López et al.,

373 2014). Unfortunately, we did not quantify the deposited salts within the pores using visual

374 techniques such as microscopic imaging. Nonetheless, the electrical conductivity, as an indirect

375 measure of salinity, showed the existence of three horizons resulting from the transport and 376 accumulation of salt in the soil column. Therefore, it is very likely that transport, dissolution and 377 precipitation of salts modified the hydrodynamic properties of the soil as evaporation occurred 378 (Benavente et al., 1999; Fierro, 2015; Nachshon and Weisbrod, 2015). All this literature review

379 shows that there is still no clear consensus about the impact of salt precipitation inside salty soils 380 and more experimental studies, with enhanced capabilities to observe salt movement and 381 precipitation would be required. 
To address the spatial variability of the soil properties, we divided the soil profile intro

383 three horizons of different thicknesses for the two studied water table levels. For each horizon we

384 optimized their hydrodynamic and thermal properties to fit the observed values, which produced

385 the parameters presented in Table 3. This approach overcomes the limitation of the SiSPAT 386 model, which does not account for salt transport, but increases significantly the number of

387 parameters. As the objective was to analyze the calculated evaporation fluxes, we consider that

388 the model should simulate the moisture and thermal profiles as close as possible to those

389 observed, in order to accomplish the correct interpretation.

Figure 5 compares the experimental water retention curve and those fitted for the three horizons of the soil profile (for water tables located at 0.75 and $0.40 \mathrm{~m}$ depth). For both water table depths, the shallower soil horizons (H1 and H2) show an increase in their capacity to retain

393 water, while the deeper horizon (H3) shows the opposite trend and reduces its capacity to hold

394 water. Even when the fitted water retention curves show small differences when compared to the

395 vertically uniform water retention properties, the changes are relevant to describe the water

396 content and temperature profile within the soil column. The fitted water retention curves (Figure

397 5) for horizons $\mathrm{H} 1, \mathrm{H} 2$ and $\mathrm{H} 3$ show a behavior that is consistent with upward salt transport. The

398 salts that were in the lower parts of the soil matrix dissolved as the soil column wetted from

399 below. This dissolution increased the pore size and reduced the capacity of the soil to retain

400 water. As the salts were dissolved in the lower parts of the soil column, they began to move

401 upwards as a consequence of the evaporation fluxes. Once the liquid water evaporated at

402 shallower parts of the soil, salts are being accumulated and precipitation reactions occur. This salt

403 precipitation increases the capacity of the soil to retain water, which can occur due to a reduction 
404 in the pore space (Vásquez et al., 2013) or due to hygroscopy (Tóth et al., 2012), which is the

405 ability of the salts to attract and retain water molecules from the surroundings. Even when the

406 fitted water retention curves show minor differences when compared to the vertically uniform

407 water retention curve derived from experimental measurements, their changes are relevant for 408 describing the moisture and thermal dynamics within the soil (Figures 1 and 2). These results are

409 in agreement with those obtained by Fierro (2015). The most significant variation in the hydraulic

410 parameters are associated with those related to the hydraulic conductivity curve $\left(K_{s}\right.$ and $\beta$ ) for the

$4110.40 \mathrm{~m}$ water table level. The $K_{s}$ values fitted for this water table are very small for the two

412 shallower horizons (i.e., H1 and H2) and do not correspond to the type of soil used. This

413 hydraulic conductivity reduction is likely due to a higher concentration of salts that could lead to

414 precipitation reactions, which then reduce the water flow paths (Vásquez et al., 2013). Note also

415 that in the experiments of Nachshon and Weisbrod (2015) subflorescent salt precipitation reduced

416 the pore space. As a consequence, there is a potential decrease in the unsaturated hydraulic

417 conductivity (Wissmeier and Barry, 2008). However, this pore space reduction in the liquid flow

418 path did not limit the evaporation rates in the experiments of Nachshon and Weisbrod (2015).

419 Therefore, in their experiments, which began with saturated conditions in the soil profile, the 420 evaporation rates were controlled by the diffusive vapor transport between the matrix surface and 421 the atmosphere.

4224.2 Simulation of liquid water and water vapor fluxes to locate the evaporation front 423 and sensitivity analysis 
427 upwards vapor fluxes and thermal downwards vapor fluxes coexist, the isothermal vapor flux $428\left(q_{v h}\right)$ is larger than the thermal vapor flux $\left(q_{v T}\right)$. In this area, the evaporation front is located where

429 the liquid and water vapor fluxes are equal (Braud et al., 2005a; 2009b; Hernández-López et al., 430 2014), i.e., at depths of 0.12 and $0.03 \mathrm{~m}$ for 0.75 and $0.40 \mathrm{~m}$ water table levels, respectively. In 431 region 2 for the $0.75 \mathrm{~m}$ water table depth, the liquid water flux dominates and net water transfer 432 is directed upwards. On the contrary, when the water table was located at $0.40 \mathrm{~m} \mathrm{depth}$, the net 433 water transfer is directed downwards (being the liquid water flux the main water transfer 434 mechanism). This downward liquid flux implies a condensation process within the soil profile, 435 which may contribute to water storage in this portion of the soil (unfortunately, such 436 condensation was not measured experimentally due to the low vertical resolution of the 437 observations). In this area, the isothermal vapor flux is zero and the downwards thermal vapor 438 flow is smaller as depth increases. In region 3, the water vapor flux is very small. These results 439 indicate that evaporation occurs in the upper soil profile, and that the position of the evaporation 440 front is closer to the soil surface as the water table depth reduces. In the area close to the surface 441 where evaporation takes place, the upward vapor flux caused by pressure gradients is larger than 442 the downward vapor flux due to temperature gradients (Konukcu et al., 2004; Gran et al., 2011; 443 Hernández-López et al., 2014).

444 It is interesting to note that the experiments of Hernández et al. (2014) assumed that 445 steady state was reached when the experimental variables varied in less than $1 \%$. However, in the 
446 previous discussion the directions of the net water flux in regions 1 and 2 are different, which

447 contradicts the principle of mass conservation under steady state conditions. Because the SiSPAT

448 model has been conceived to respect the energy and mass balance, and it has proven its

449 robustness for isotopic transport in very constraining conditions (see for instance Braud et al., 450 2005a), mass conservation is being correctly solved in the model. Therefore, even when the 451 experimental variables did not changed significantly after 20 days of fixing the water level, the 452 system is likely to be under transient conditions. Note also that the experimental conditions of 453 Hernández-López et al. (2014), may not favor steady state establishment because although the 454 laboratory temperature and humidity were controlled; the forcing temperature above the soil 455 column and at the bottom of the column was varying in time. When analyzing the model results, 456 there is a change in soil moisture storage, even after 20 days, and the sign of change in water 457 content is consistent with the explanation provided in the previous paragraph in terms of fluxes 458 directions. In this case, even if the fluxes at the top and at the bottom of the soil column were the 459 same, steady state was not reached after 20 days as the total flux inside the intermediate part of 460 the column was not equal to that modeled at the boundaries. We tested a run lasting 500 days to 461 see if it was possible to reach steady state and we found that for the $0.75-\mathrm{m}$ water table depth, 462 steady state was reached after $\sim 150$ days with soil water content and temperature profiles very 463 similar to those shown in Figure 2 (see Figure 6). For the 0.40-m water table depth, the time to 464 reach steady state was longer ( 400 days) and the shape of the profile is quite different, as shown 465 in Figure 6. These results suggest that the experiments performed by Hernández-López et al. 466 (2014) were not under steady state conditions after 20 days of fixing the water table level. 
468 boundary condition on the results. In these simulations, the known flux equal to the evaporation 469 rate at the top of the soil profile was replaced with a known pressure of $0.45 \mathrm{~m}$ (to simulate a 470 water table depth at $0.75 \mathrm{~m}$ from the surface of the 1.2-m depth column). With this boundary 471 condition (imposed soil water pressure), it was found that after 500 days steady state conditions 472 were not achieved and the simulation results were not realistic. In fact, given the model 473 configuration, drainage was simulated at the bottom of the column.

475 laboratory experiments as the model provides information and explanation about possible active 476 processes that are not accessible to the experimental observations. Especially in terms of the 477 interplay between liquid and vapor fluxes. The physical model also allows testing various 478 boundary conditions and soil hydraulic properties, which would not be accessible using 479 laboratory experiments only.

It is important to point out that from the experimental results, as discussed by Hernández481 López et al. (2014), it is not easy to locate the evaporation front. This issue occurred because of 482 the too low spatial resolution $(0.05 \mathrm{~m})$ of the instruments used in their experiments. From the 483 thermal profile when the water table was at $0.75 \mathrm{~m}$ depth, Hernández-López et al. (2014) 484 estimated that the location of the evaporation front was between the soil surface and a depth of $485 \sim 0.10$ m. For shallower water tables, Hernández-López et al. (2014) were unable to determine the 486 position of the evaporation front and only concluded that it was located between the soil surface 487 and $\sim 0.05 \mathrm{~m}$ depth (the location of their shallowest sensor). This difficulty can be overcome with 
high resolution measurements or with the use of a numerical model. Indeed, our numerical model allowed determining the evaporation front $(0.12$ and $0.03 \mathrm{~m}$ when the water table was at 0.75 and

$490 \quad 0.40 \mathrm{~m}$ depth, respectively). Note also that, as described before, the location of the evaporation

491 front obtained from the numerical model agrees fairly well with the observations of Hernández-

492 López et al. (2014).

The sensitivity analysis permitted to understand how the enhancement and tortuosity

494 factors affect cumulative evaporation (Figure 4). In terms of the enhancement factor, Cass et al.

495 (1984) recommend using $a=9.5$ for a sandy textured soil when determining $\eta$ using equation

496 (16). Although the Cass et al. (1984) model is generally accepted to determine the vapor thermal

497 diffusivity, the recommended value of $a$ does not lead to an acceptable fit with the experimental

498 values. On the contrary, Philip and de Vries (1957) suggests $\eta=1.5$ for sandy soils. This value of

$499 \quad \eta$ yields simulated cumulative evaporation values more consistent with those observed in the

500 experiments (Hernández-López et al., 2014). Note also that when $\tau_{a}$ is calculated using the

501 expression proposed by Millington and Quirk (1961), the cumulative evaporation for both

502 experiments are simulated correctly.

Figure 7 compares the vapor fluxes $\left(q_{v}\right)$ for the different values of $\tau_{a}$ and $\eta$ presented in

504 Figure 4, and for both water table levels. In general, when $\tau_{a}$ increases, the vapor flux increases in 505 the upward direction. This behavior is more evident between $\sim 0-0.13 \mathrm{~m}$ depth when the water 506 table level was at $0.75 \mathrm{~m}$, and between $\sim 0-0.05 \mathrm{~m}$ depth when the water table was at $0.40 \mathrm{~m}$. It is 507 also interesting to observe that for large values of $\eta$, the net water flux direction changes from 508 upwards to downwards. Moreover, when $\eta$ increases, condensation at the soil surface occurs 
509 (Figures 4 and 6). In addition to the magnitude and direction, in some cases the position of the

510 evaporation front also changes. By increasing $\tau_{a}$, the evaporation front is located deeper in the

511 soil (starting from the surface of the soil).

512 Although changes in cumulative evaporation and vapor flux due to changes in $\tau_{a}$ are

513 important, the influence of variations in $\eta$ is even more significant, resulting sometimes in major

514 condensation. These results, which disagree with the experimental observations, allow discarding

515 different set of calibrated parameters that yields non-physical results and thus, minimize the

516 problem of equifinality. For instance, as shown in Figure 4 for a water table located at $0.75 \mathrm{~m}$

517 depth and using a variable $\eta$ (equation (16) with $a \geq 4.0$ ), even when the soil water content and

518 the temperature profiles are represented satisfactorily, the modeled cumulative evaporation after

519 reaching quasi steady state is negative, i.e., the model predicts water condensation at the soil

520 surface. Instead, the experimental observations show a cumulative evaporation of $\sim 0.9 \mathrm{~mm}$.

\subsection{Model limitations}

Our approach has some limitations that need to be understood in order to perform a

523 correct interpretation of the results. One important aspect that the SiSPAT model does not

524 represent is fluid flow due to solute concentration effects (Barbour and Fredlund, 1989;

525 Nachshon et al., 2011). Indeed, as shown by Nassar et al. (1989), the osmotic gradient can be an

526 important driving force for water movement in unsaturated soils with high clay content. We used

527 the approach proposed by Barbour and Fredlund (1989) to determine the order of magnitude of

528 the liquid and water vapor fluxes due to solute concentration gradients. In this analysis, we

529 assumed that sodium chloride $(\mathrm{NaCl})$ was the main component that contributes to the osmotic 
530 pressure and that the maximum solute concentration occurred at saturated conditions ( 25 wt $\%$

531 for $\mathrm{NaCl}$ ). Also, the observed experimental conditions were utilized to evaluate the temperature

532 in the Van't Hoff equation (Barbour and Fredlund, 1989), and the experimental soil water content

533 was used to determine the osmotic flow of water within the soil. This analysis resulted in osmotic

534 fluid flows on the order of $10^{-11} \mathrm{~m} / \mathrm{s}$, which are at least one order of magnitude smaller than those

535 obtained using SiSPAT. Thus, in our experiments we expect a small contribution of the osmotic

536 flow of water in the liquid and the gaseous phase.

537 It is also important to discuss that discrepancy between experimental data and model

538 predictions has led to the development of vapor-flux enhancement factors, such as $\eta$ (Philip and

539 de Vries, 1957; Cass et al., 1984). The inclusion of these enhancement factors in numerical

540 models, such as that used in this work, is due to a lack of sufficiently accurate description of

541 vapor dynamics to represent correctly the soil physics processes that occur during evaporation

542 (Assouline et al., 2013). There are many processes that explain this vapor-flux enhancement

543 (Philip and de Vries, 1957; Cass et al., 1984; Bachmann et al., 2001; Grifoll et al., 2005; Shokri

544 et al., 2009; Shahraeeni and Or, 2012; Assouline et al., 2013; Trautz et al., 2015). For instance,

545 investigations have shown that with proper account of capillary flow, continuity and pathways,

546 no vapor-flux enhancement factors are required (Grifoll et al., 2005; Shokri et al., 2009).

547 Shahraeeni and Or (2012) demonstrated that water transport can be enhanced by $\sim 10 \%$ when

548 isolated liquid-phase bridges are present due to a reduction in the gaseous diffusion path length,

549 and that thermal gradients can enhance water vapor diffusion. Also, vapor flux from within the

550 soil profile can be enhanced by thermally driven convective transport mechanisms (Bachmann et 
551 al., 2001). Recently, Trautz et al. (2015) argued that non-equilibrium phase change is also

552 responsible for vapor-flux enhancement.

From the vapor-flux enhancement mechanisms that have been reported in the scientific

554 literature, we hypothesize that a combination between non-equilibrium phase change and cyclic

555 thermal conditions typically found between day and night, could be responsible for the vapor-flux

556 enhancement observed in our experiments. When cyclic thermal conditions are present, two

557 processes can drive soil evaporation: evaporation from the soil surface into the atmosphere during

558 early morning and subsurface evaporation limited by Fickian Diffusion until late afternoon. As

559 explained by Assouline et al. (2013), evaporation from the soil surface depletes the water

560 condensed and redistributed during nighttime. After the depletion of this water, Fickian diffusion

561 becomes the governing process and increases the thickness of the dry layer of soil observed at the

562 soil surface. In addition, as discussed by Trautz et al. (2015), non-equilibrium processes are

563 relevant when cyclic thermal conditions occur.

564 Many studies have used laboratory columns, but very few of them have focused on

565 understanding natural highly saline dry soils. Moreover, typical column experiments do not deal

566 with natural highly salty soils and low water content. Our results show that evaporation in

567 initially dry soils produce moisture content and conductivity distributions that are atypical. This

568 behavior has not been reported in the literature, which typically reports experiments in which an

569 initially saturated soil column is subsequently dried out. 
572 of aquifer depletion in zones such as those located in the Altiplano basins of northern Chile, we

573 conducted a modeling study to investigate evaporation processes under non-isothermal

574 conditions. A model that couples liquid water, water vapor, and heat transport was developed and

575 calibrated using laboratory observations performed in a homogeneous natural soil column that

576 was filled with soil from the Huasco salt flat, Chile. Modeled and experimental results only

577 agreed when the soil hydrodynamic properties (water retention and hydraulic conductivity curve)

578 were calibrated. The change in the soil hydrodynamic properties can be explained by

579 precipitation/dissolution reactions that are driven by evaporation and that yield a stratified soil

580 profile when quasi steady state conditions were achieved.

Model results showed a good agreement with the experimental observations of the soil

582 water content and thermal profiles, and also reproduced the experimental cumulative evaporation

583 with differences of 0.01 and $0.67 \mathrm{~mm}$ for the 0.75 and $0.40 \mathrm{~m}$ water table depths, respectively.

584 Model results permitted to distinguish three characteristic zones in the soil profile. The first zone

585 (region 1) is located near the surface, where the total flux is directed upwards and the water

586 movement is mainly due to vapor fluxes driven by pressure gradients. The second zone (region 2)

587 is located below region 1 and is where the liquid water flux dominates. The third zone (region 3)

588 is where the liquid water flux is very small. Model results indicate that evaporation occurs in the

589 upper soil profile and that the position of the evaporation front depends on the water table depth.

A sensitivity analysis allowed understanding the impact of the enhancement factor and the

591 tortuosity on the cumulative evaporation. The enhancement factor had the largest influence on 
592 cumulative evaporation that can even result in condensation at the soil surface. This analysis also

593 allowed discarding different set of calibrated parameters that yield non-physical conditions,

594 which minimize the problem of equifinality. The results presented in this study are important as

595 they allow understanding the main evaporation processes that occur in bare soils from Altiplano

596 basins where these processes are not well understood.

\section{Acknowledgments}

598 The authors acknowledge funding from the Chilean National Commission for Scientific

599 and Technological Research (CONICYT/FONDECYT/1130522). F. Suárez and J. Gironás thank

600 the Centro de Desarrollo Urbano Sustentable for additional support (CEDEUS -

601 CONICYT/FONDAP/15110020), and J. Gironás also acknowledges the Centro de Investigación

602 para la Gestión Integrada de Desastres Naturales (CIGIDEN - CONICYT/FONDAP/15110017).

603 The modeling study presented in this paper was possible thanks to a grant for a stay of M.F.

604 Hernández-López at Irstea, funded by Pontificia Universidad Católica de Chile and Irstea. We

605 also thank the anonymous reviewers for the positive comments that improved this paper.

\section{References}

607 Abu-El-Sha'r WY, Abriola LM. 1997. Experimental assessment of gas transport mechanisms in 608 natural porous media: parameter evaluation. Water Resource Research, 33(4): 505-516.

609 Alazard M, Leduc C, Travi Y, Boulet G, Ben Salem A. 2015. Estimating evaporation in semi-arid 610 areas facing data scarcity: example of the El Haouareb dam (Merguellil catchment, Central 611 Tunisia). Journal of Hydrology: Regional Studies 3:265-284. 
612 Assouline S, Tyler SW, Selker JS, Lunati I, Higgins CW, Parlange MB. 2013. Evaporation from a shallow water table: diurnal dynamics of water and heat at the surface of drying sand. Water Resources Research, 49:4022-4034.

615 Bachmann J, Horton R, van del Ploeg RR. 2001. Isothermal and nonisothermal evaporation from four Sandy soils of different water repelency. Soil Sci. Soc. Am. J., 65, 1599-1607.

Barbour SL, Fredlund DG. 1989. Mechanisms of osmotic flow and volume change in clay soils. Can. Geotech. J., 26, 551-562. changes induced by salt pressure crystallisation in porous media of stone. Journal of Crystal

Boulet G, Braud I, Vauclin M. 1997. Study of the mechanisms of evaporation under arid Growth, 204: 168-178. conditions using a detailed model of the soil-atmosphere continuum. Application to the EFEDA I experiment. Journal of Hydrology, 193(1-4): 114-141. and energy balance model designed for regionalization and remote sensing data utilization. Agricultural and Forest Meteorology, 105: 117-132.

Braud I, Bariac T, Gaudet JP, Vauclin M. 2005a. SiSPAT-Isotope, a coupled heat, water and stable isotope (HDO and H2180) transport model for bare soil. Part I: Model description and first verification, J. Hydrology, 309(1-4), 277-300.

631 Braud I, Bariac T, Vauclin M, Boujamlaoui Z, Gaudet JP, Biron Ph, Richard P. 2005b. SiSPAT632 Isotope, a coupled heat, water and stable isotope (HDO and H218O) transport model for 
bare soil. Part II: Evaluation and sensitivity tests using two laboratory data sets, J. Hydrology, 309(1-4), 301-320.

635 Braud I, Biron P, Bariac T, Richard P, Canale L, Gaudet JP, Vauclin M. 2009a. Isotopic composition of bare soil evaporated water vapor. Part I: RUBIC IV experimental setup and results. Journal of Hydrology, 369: 1-16.

Braud I, Bariac T, Biron P, Vauclin M. 2009b. Isotopic composition of bare soil evaporated water flow. Part II: Modeling of RUBIC IV experimental results. Journal of Hydrology, 369: 17-

641 Braud I, Dantas-Antonino AC, Vauclin M, Thony JL, Ruelle P. 1995. A simple soil-plantatmosphere transfer model (SiSPAT) development and field verification. Journal of Hydrology, 166: 213-250.

644 Brooks RH, Corey AT, 1964. Hydraulic properties of porous media. Hydrology paper 3, 645 Colorado State University, Fort Collins, 27 pp.

646 Cahill AT, Parlange MB, 1998. On water vapor transport in field soils. Water Resources 647 Research, 34(4): 731-739.

648 Cass A, Campbell GS, Jones TL. 1984. Enhacement of thermal water vapor difussion in soil. Soil 649 Science Society of America Proceedings, 48: 25-32.

650 de la Fuente A, Niño Y. 2010. Temporal and spatial features of the thermohydrodynamics of 651 shallow salty lagoons in northern Chile. Limnology and Oceanography 55:279-288.

652 Fierro V. 2015. SAR effects on evaporation fluxes from shallow groundwater. M. Sc. Thesis, 653 Pontificia Universidad Católica de Chile, Santiago, Chile. 
654 Gran M, Carrera J, Massana J, Saaltink MW, Olivella S, Ayora C, Lloret A. 2011. Dynamics of water vapor flux and water separation processes during evaporation from a salty dry soil. 656 Journal of Hydrology, 396: 215-220.

657 Grifoll J, Gastó JM, Cohen Y. 2005. Non-isothermal soil water transport and evaporation. Advances in Water Resources, 28: 1254-1266.

659 Hernández-López MF, Gironás J, Braud I, Suárez F, Muñoz JF. 2014. Assessment of evaporation and water fluxes in a column of dry saline soil subject to different water table levels. Hydrological Processes, 28(10): 3655-3669.

662 Johnson E, Yáñez J, Ortiz C, Muñoz J. 2010. Evaporation from shallow groundwater in closed basins in the Chilean Altiplano. Hidrological Sciences Journal, 55(4): 624-635.

664 Kampf S, Tyler S, Ortiz C, Muñoz J, Adkins P. 2005. Evaporation and land surface energy 665 budget at the Salar de Atacama, northern Chile. Journal of Hydrology 310:236-252.

666 Konukcu F, Istanbulluoglu A, Kocaman I. 2004. Determination of water content in drying soils: incorporating transition from liquid phase to vapour phase. Australian Journal of Soil Research 42(1): 1-8.

Laurent JP, Guerre-Chaley C. 1995. Influence de la teneur en eau et de la température sur la conductivité thermique du béton cellulaire autoclave. Materials and Structures, 28:464-472.

671 Lictevout E, Maass C, Córdoba D, Herrera V, Payano R. 2013. Recursos Hídricos Región de 672 Tarapacá - Diagnóstico y Sistematización de la Información. CIDERH. ISBN:978 956302 673081 - 6. Available at: http://www.ciderh.cl/documentos/recursos-hidricos-region-de674 tarapaca/ (last accessed July 2016). 
675 Liu S, Lu L, Mao D, Jia L. 2007. Evaluating parametrizations of aerodynamic resistance to heat 676 transfer using field measurements. Hydrology and Earth System Sciences, 11: 769-783.

677 Millington RJ, Quirk JM. 1961. Permeability of porous solids. 57. Transaction of the Faraday $678 \quad$ Society, 57: 1200-1207.

679 Milly PCD. 1984. A simulation analysis of thermal effects on evaporation from soil. Water $680 \quad$ Resources Research, 20(8): 1087-1098.

681 Nachshon U, Weisbroad N, Dragila MI, Grader A. 2011. Combined evaporation and salt 682 precipitation in homogeneous and heteregenous porous media. Water Resource Research, 47: W03513, doi:10.1029/2010WR009677.

684 Nachshon U, Weisbrod N. 2015. Beyond the Salt Crust: On Combined Evaporation and 685 Subflorescent Salt Precipitation in Porous Media. Transport in Porous Media, 110: 295310. DOI: $10.1007 / \mathrm{s} 11242-015-0514-9$.

Nassar IN, Horton R. 1989. Water transport in unsaturated nonisothermal salty soil: II. 688 Theoretical development. Soil Science Society of America Proceedings, 53: 1330-1337.

689 Novak MD. 2010. Dynamics of the near-surface evaporation zone and corresponding effects on the surface energy balance of a drying bare soil. Agricultural and Forest Meteorology, $1501358-1365$.

693

Penman HL. 1940. Gas and vapor movement in the soil. I. The diffusion of vapors through porous solids. The Journal of Agricultural Science, 30(4): 570-581.

694 Philip JR, de Vries DA. 1957. Moisture movement in porous materials under temperature 695 gradient. Transactions American Geophysical Union, 38: 222-232. 
696

697

698

699

700

701

702

703

704

705

706

707

708

709

710

711

712

713

714

715

716

717

Saito H, Simunek J, Mohanty BP. 2006. Numerical Analysis of Coupled Water, Vapor, and Heat Transport in the Vadose Zone. Vadose Zone Journal, 5: 784-800.

Schulz S, Horovitz M, Rausch R, Michelsen N, Mallast U, Köhne M, Siebert C, Shüth C, AlSaud M, Merz R. 2015. Groundwater evaporation from salt pans: examples from the eastern Arabian Peninsula. Journal of Hydrology. doi:10.1016/j.jhydrol.2015.10.048

Scotter DR. 1974. Salt and water movement in relatively dry soil. Australian Journal of Soil Research, 12(1): 27-35.

Sghaier N, Geoffroy S, Prat M, Eloukabi H, Nasrallah SB. 2014. Evaporation-driven growth of large crystallized salt structures in a porous medium. Phys. Rev. E 90, 042402

Shahraeeni E, Or D. 2012. Pore scale mechanisms for enhanced vapor transport through partially saturated porous media. Water Resour. Res., 48, W05511, doi:10.1029/2011WR011036.

Shokri NP, Lehmann P, Or D. 2009. Critical evaluation of enhancement factors for vapor transport through unsaturated porous media. Water Resour. Res., 45, W10433, doi:10.1029/2009WR007769.

Shuttleworth WJ, Wallace JS. 1985. Evaporation from sparse crops an energy combination theory. Quarterly Journal of the Royal Meteorological Society, 111: 839-855.

Tang J, Zhuang Q. 2008. Equifinality in parameterization of process-based biogeochemistry models: A significant uncertainty source to the estimation of regional carbon dynamics, Journal of Geophysical Research, 113, G04010, doi:10.1029/2008JG000757.

Tóth B, Makó A, Guadagnini A, Tóth G. 2012. Water retention of salt-affected soils: quantitative estimation using soil survey information. Arid Land Research and Management 26:103121. 
718 Trautz AC, Smits KM, Cihan A. 2015. Continuum-scale investigation of evaporation from bare

719 soil under different boundary and initial conditions: An evaluation of nonequilibrium phase

720 change, Water Resour. Res., 51, 7630-7648, doi:10.1002/2014WR016504.

721 van Genuchten MT. 1980. A closed-form equation for predicting the hydraulic conductivity on

722 unsatured soils. Soil Science Society of America Proceedings, 44(5): 892-898.

723 Vásquez C, Ortiz C, Suárez F, Muñoz JF. 2013. Modeling flow and reactive transport to explain

724 mineral zoning in the Atacama salt flat aquifer, Chile. Journal of Hydrology, 490:114-125.

725 Weisbrod N, Nachshon U, Dragila M, Grader A. 2014. Micro-CT analysis to explore salt 726 precipitation impact on porous media permeability. Transport and Reactivity of Solutions in 727 Confined Hydrosystems. Part of the series NATO Science for Peace and Security Series C: $728 \quad$ Environmental Security, 231-241.

729 Wissmeier L, Barry DA. 2008. Reactive transport in unsaturated soil: Comprehensive modeling 730 of the dynamic spatial and temporal mass balance of water and chemical components, $731 \quad$ Advances in Water Resources, 31, 858-875. 


\section{Table captions}

734 Table 1: Coefficients and variables used in the SiSPAT model to estimate liquid water and water

735 vapor flows.

736 Table 2: Model parameters, and initial and boundary conditions.

737 Table 3: Model parameters used for the three horizons.

738 Table 4: Model calibration efficiency for soil water content $(\theta)$ and temperature $(\mathrm{T})$, and

739 comparison of the experimental cumulative evaporation and the data obtained from the calibrated

740 model. 


\section{$742 \quad$ Figure captions}

743 Figure 1: Observed and modeled soil water content $(\theta)$ and temperature profiles, and observed

744 electrical conductivity $(\sigma)$ profile for different water table levels (WTL), after 20 days of fixing

745 the water table level. Model results assume a vertically homogeneous soil profile. (a) and (b)

746 show the soil water content profiles for WTL of 0.75 and $0.40 \mathrm{~m}$, respectively; (c) and (d) show

747 the temperature profiles for WTL of 0.75 and $0.40 \mathrm{~m}$, respectively; and (e) and (f) show the

748 electrical conductivity profiles for WTL of 0.75 and $0.40 \mathrm{~m}$, respectively.

749 Figure 2: Observed and modeled soil water content $(\theta)$ and temperature profiles for different

750 water table levels (WTL), after 20 days of fixing the water table level and assuming the soil

751 stratifies in three horizons (H1, H2, and H3) due to salt transport. (a) and (b) show the soil water

752 content profiles for WTL of 0.75 and $0.40 \mathrm{~m}$, respectively; (c) and (d) show the temperature

753 profiles for WTL of 0.75 and $0.40 \mathrm{~m}$, respectively.

754 Figure 3: Variation of liquid and water vapor flux along the soil profile for different water table

755 levels (WTL). (a) and (b) show the liquid flux $\left(\mathrm{q}_{\mathrm{L}}\right)$, the water vapor flux $\left(\mathrm{q}_{\mathrm{v}}\right)$ and the total water

756 flux ( $\left.\mathrm{q}_{\mathrm{total}}\right)$ for WTL of 0.75 and $0.40 \mathrm{~m}$, respectively; (c) and (d) show the thermal vapor flux

$757\left(\mathrm{q}_{\mathrm{vT}}\right)$, the isothermal (due to pressure) vapor flux $\left(\mathrm{q}_{\mathrm{vh}}\right)$, and the total vapor flux $\left(\mathrm{q}_{\mathrm{v}}\right)$ for WTL of

$758 \quad 0.75$ and $0.40 \mathrm{~m}$, respectively. Negative (positive) fluxes correspond to upward (downward)

759 movement.


761 Figure 4: Comparison of cumulative evaporation $(\mathrm{mm})$ for different tortuosity values $\left(\tau_{\mathrm{a}}\right)$ and

762 enhancement factors $(\eta)$ for the 0.75 and $0.40-\mathrm{m}$ water table levels. $\tau_{\mathrm{a}}{ }^{*}$ was calculated based on

763 equation (15) (Millington and Quirk, 1961), and equation (16) was used when $\eta=$ variable (Cass

764 et al., 1984).

765 Figure 5: Water retention curves fitted for each horizon $(\mathrm{H} 1, \mathrm{H} 2$, and $\mathrm{H} 3)$ for the $0.75 \mathrm{~m}$ water 766 table level (a), and the $0.40 \mathrm{~m}$ water table level (b).

767 Figure 6. Comparison of the soil water content and temperature profiles for the 0.75-m (a and c) 768 and $0.40-\mathrm{m}$ (b and d) water table levels (WTL), for the simulation presented in Figure 2 (black)

769 and after steady state was reached (red) when using the bottom boundary conditions equal to the 770 top evaporation flux.

771 Figure 7: Comparison of the water vapor fluxes profiles for the 0.75 and $0.40 \mathrm{~m}$ water table levels

772 (WTL). Results are shown for different tortuosity values, $\tau_{a}$, (a) and (c), and for different 773 enhancement factor values, $\eta(\mathrm{b})$ and (d). $\tau_{\mathrm{a}}{ }^{*}$ was calculated based on equation (15) (Millington 774 and Quirk, 1961), and equation (16) was used when $\eta=$ variable (Cass et al., 1984). Negative 775 (positive) fluxes correspond to upward (downward) movement. 
Table 1: Coefficients and variables used in the SiSPAT model to estimate liquid water and water vapor flows.

778

$\left.\begin{array}{ll}\hline \text { Parameter } & \text { Formula } \\ \hline \text { Saturated vapor pressure } & e_{s a t}(T)=618.78 \exp \left(\frac{17.27(T-273.15)}{T-35.86}\right) \\ \text { Relative Humidity } & h_{u}=\exp \left(\frac{h g}{R T}\right) \\ \text { Vapor density } & \rho_{v}=\frac{h_{u} e_{s a t}(T)}{R T} \\ \text { Diffusivity of water vapor in the air (Philip and De Vries, 1957) } & D_{a}=2.17 \times 10^{-5}\left(\frac{T}{273.15}\right)^{1.88} \\ \text { Isothermal diffusivity of water vapor (Philip and De Vries, 1957) } & D_{v h}=\tau_{a} F(\varepsilon-\theta) D_{a} \frac{P_{a t m}}{P_{a t m}-e_{v}} \frac{\partial \rho_{v}}{\partial h} \\ \text { Thermal diffusivity of water vapor (Philip and De Vries, 1957) } & D_{v T}=\eta F(\varepsilon-\theta) D_{a} \frac{P_{a t m}}{P_{a t m}-e_{v}} \frac{\partial \rho_{v}}{\partial T} \\ \text { Apparent thermal conductivity (Laurent and Guerre-Chaley, 1995) } & \lambda=\lambda_{0}+a_{L G} \frac{\theta}{\theta_{S}}+b_{L G}\left(1-\exp \left\{-c_{L G}\left(\frac{\theta}{\theta_{S}}\right)^{d_{L G}}\right.\right.\end{array}\right)$

$\theta$ : volumetric water content $\left(\mathrm{m}^{3} \mathrm{~m}^{-3}\right) ; \theta_{s}$ : saturated volumetric water content $\left(\mathrm{m}^{3} \mathrm{~m}^{-3}\right) ; \theta_{r}$ : residual volumetric water content $\left(\mathrm{m}^{3} \mathrm{~m}^{-3}\right) ; \alpha$ : inverse of the air-entry pressure $\left(\mathrm{m}^{-1}\right) ; h$ : water suction $(\mathrm{m}) ; n$ and $m$ are empirical fitting parameters of the water retention curve; $K_{s}$ : saturated hydraulic conductivity $\left(\mathrm{m} \mathrm{s}^{-1}\right)$; $T$ : temperature $(\mathrm{K}) ; g$ : gravitational acceleration $\left(\mathrm{m} \mathrm{s}^{-2}\right) ; R$ : universal gas constant $\left(\mathrm{J} \mathrm{kg}^{-1}\right) ; \tau_{a}$ : soil tortuosity $(-) ; \lambda_{0}$ : dry thermal conductivity; $P_{a t m}$ : atmospheric pressure $(\mathrm{Pa}) ; e_{v}$ : partial pressure of water vapor (Pa); $\eta$ : enhancement factor $(=1.5)$; and $a_{L G}, b_{L G}, c_{L G}$, and $d_{L G}$ are empirical fitting parameters of the 
Table 2: Model parameters and initial and boundary conditions.

\begin{tabular}{|c|c|c|}
\hline Parameter & Value & Observations \\
\hline Saturated moisture content $\theta_{s}\left(\mathrm{~m}^{3} \mathrm{~m}^{-3}\right)$ & 0.3 & Measured \\
\hline Residual moisture content $\theta_{r}\left(\mathrm{~m}^{3} \mathrm{~m}^{-3}\right)$ & 0.0 & Parameter fitted from the water retention data \\
\hline Inverse of the air-entry pressure $\alpha\left(\mathrm{m}^{-1}\right)$ & 0.7160 & Parameter fitted from the water retention data \\
\hline$n(-)$ & 1.1859 & Parameter fitted from the water retention data \\
\hline Saturated hydraulic conductivity $K_{s}\left(\mathrm{~m} \mathrm{~s}^{-1}\right)$ & $1.06 \times 10^{-5}$ & Measured \\
\hline Porosity (-) & 0.3 & Assumed equal to the saturated moisture content \\
\hline$a_{L G}$ & 0.3 & \\
\hline$b_{L G}$ & 0.5 & \\
\hline$c_{L G}$ & 1.0 & $\begin{array}{l}\text { Parameters of the apparent thermal conductivity from the } \\
\text { Laurent and Guerre-Chaley model (1995). }\end{array}$ \\
\hline$d_{L G}$ & 4.0 & \\
\hline$\lambda_{0}$ & 0.12 & \\
\hline Initial soil temperature conditions & $T(z)$ & $\begin{array}{l}\text { Linear interpolation of temperature measurements in the soil at } \\
0.05,0.10,0.15,0.20,0.25,0.30,0.35,0.40 \text { and } 0.45 \mathrm{~m} \text {. The } \\
\text { initial time corresponds to the } 1^{\text {st }} \text { day after fixing the water table } \\
\text { depth. }\end{array}$ \\
\hline Initial soil pressure conditions & $h(z)$ & $\begin{array}{l}\text { Determined from moisture content measurements at } 0.05,0.10 \text {, } \\
0.15,0.20,0.25,0.30,0.35,0.40 \text { and } 0.45 \mathrm{~m} \text { depth using the } \\
\text { water retention curve. The initial time corresponds to the } 1^{\mathrm{st}} \text { day } \\
\text { after fixing the water table depth. }\end{array}$ \\
\hline \multirow{3}{*}{ Boundary conditions at the bottom } & Known flux & $\begin{array}{l}\text { A known water flux equal to the evaporation flux This } \\
\text { boundary condition was then evaluated in a sensitivity analysis. }\end{array}$ \\
\hline & & \\
\hline & $T(t)$ & $\begin{array}{l}\text { Extrapolated from the measurements of the thermal profile } \\
\text { within the soil column. }\end{array}$ \\
\hline Boundary condition on the surface & $T(t)$ & Temperature measured at the soil column surface. \\
\hline
\end{tabular}


Table 3: Model parameters used for the three horizons.

\begin{tabular}{|c|c|c|c|c|c|c|}
\hline Depth of the water table $(\mathrm{m})$ & 0.75 & & & 0.40 & & \\
\hline Horizon & $\mathrm{H} 1$ & $\mathrm{H} 2$ & $\mathrm{H} 3$ & $\mathrm{H} 1$ & $\mathrm{H} 2$ & $\mathrm{H} 3$ \\
\hline Horizon depth (m) & 0.20 & 0.10 & 0.90 & 0.15 & 0.15 & 0.90 \\
\hline Saturated moisture content, $\theta_{s}\left(\mathrm{~m}^{3} \mathrm{~m}^{-3}\right)$ & 0.300 & 0.300 & 0.300 & 0.300 & 0.300 & 0.300 \\
\hline Residual moisture content, $\theta_{r}\left(\mathrm{~m}^{3} \mathrm{~m}^{-3}\right)$ & 0.033 & 0.000 & 0.000 & 0.033 & 0.000 & 0.000 \\
\hline Inverse of the air entry pressure, $\alpha\left(\mathrm{cm}^{-1}\right)$ & 0.6677 & 0.7163 & 0.6667 & 0.40 & 0.555 & 0.6667 \\
\hline Shape parameter of the water retention curve, $n(-)$ & 1.2370 & 1.16 & 1.2470 & 1.2370 & 1.1859 & 1.2470 \\
\hline Saturated hydraulic conductivity, $K_{s}\left(\mathrm{~m} \mathrm{~s}^{-1}\right)$ & $1.5 \times 10^{-5}$ & $5.0 \times 10^{-5}$ & $1.0 \times 10^{-5}$ & $1.0 \times 10^{-8}$ & $1.5 \times 10^{-8}$ & $1.0 \times 10^{-5}$ \\
\hline $\begin{array}{l}\text { Shape factor of the hydraulic conductivity curve, } \\
\beta(-)\end{array}$ & 18 & 18 & 18 & 25 & 30 & 30 \\
\hline$a_{L G}$ & 0.300 & & & 0.734 & & \\
\hline$b_{L G}$ & 0.9 & & & 0.3 & & \\
\hline$c_{L G}$ & 35.0 & & & 35.0 & & \\
\hline$d_{L G}$ & 5.00 & & & 3.82 & & \\
\hline$\lambda_{0}$ & 0.12 & & & 0.50 & & \\
\hline
\end{tabular}


797 Table 4: Model calibration efficiency for soil water content $(\theta)$ and temperature $(\mathrm{T})$, and comparison of the

798 experimental cumulative evaporation and the data obtained from the calibrated model.

799

\begin{tabular}{ccc}
\cline { 2 - 3 } & \multicolumn{2}{c}{ Depth to groundwater table (m) } \\
\cline { 2 - 3 } & 0.75 & 0.40 \\
\hline$B_{\theta}\left(\mathrm{m}^{3} \mathrm{~m}^{-3}\right)$ & 0.0095 & 0.020 \\
$E_{\theta}(-)$ & 0.002 & -0.0003 \\
$R M S E_{\mathrm{T}}\left({ }^{\circ} \mathrm{C}\right)$ & 0.985 & 0.50 \\
$B_{\mathrm{T}}\left({ }^{\circ} \mathrm{C}\right)$ & 2.08 & 2.61 \\
$E_{\mathrm{T}}(-)$ & 0.40 & -2.41 \\
\hline Experimental cumulative evaporation $(\mathrm{mm})$ & 0.67 & 0.46 \\
\hline Modeled cumulative evaporation $(\mathrm{mm})$ & 0.85 & 5.78 \\
\hline
\end{tabular}

800

$R M S E$ : root mean square error; $B$ : bias; $E$ : Nash-Sutcliffe efficiency

801

802 

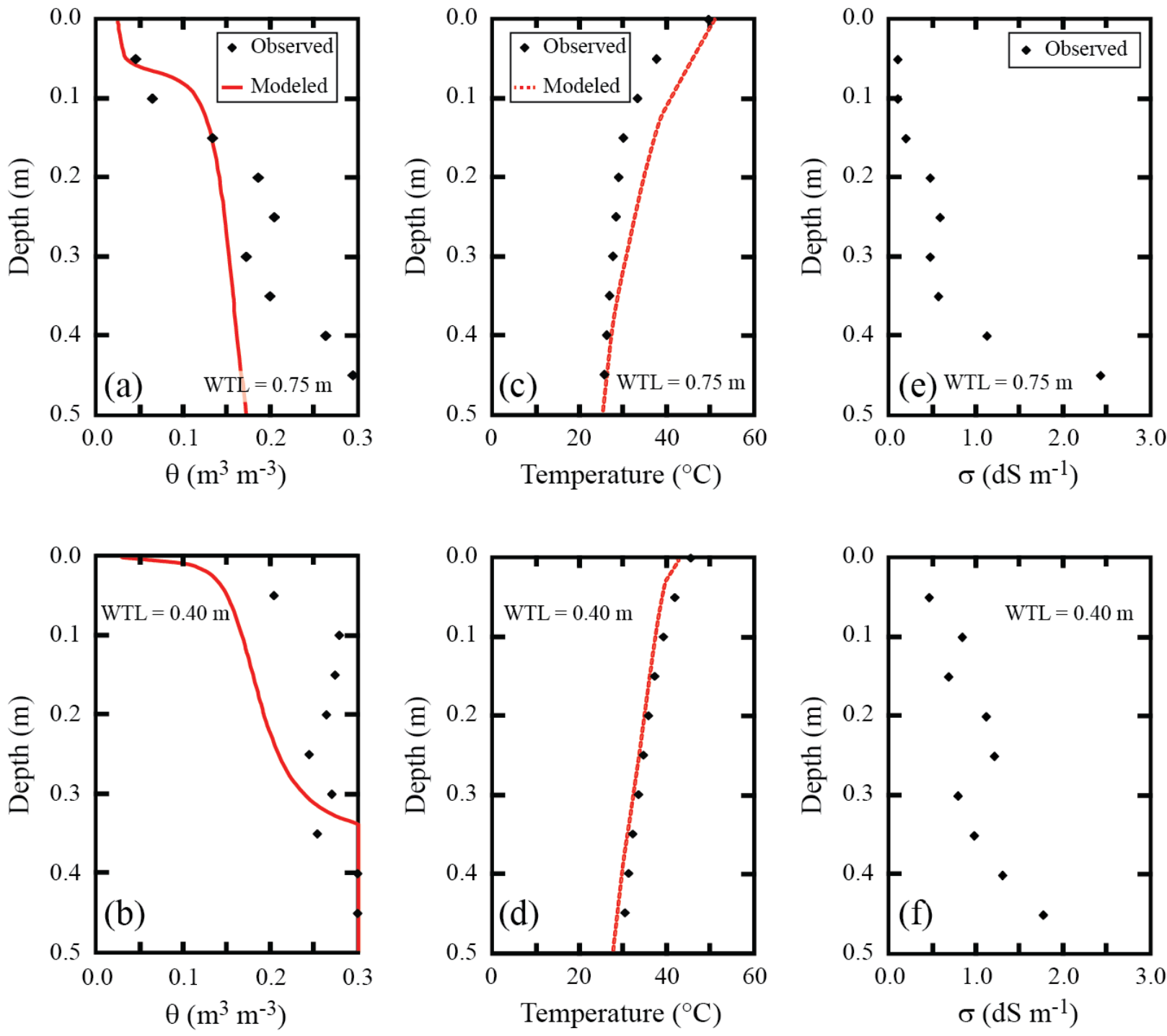

804 Figure 1: Observed and modeled soil water content $(\theta)$ and temperature profiles, and observed electrical conductivity

$805(\sigma)$ profile for different water table levels (WTL), after 20 days of fixing the water table level. Model results assume

806 a vertically homogeneous soil profile. (a) and (b) show the soil water content profiles for WTL of 0.75 and 0.40 m,

807 respectively; (c) and (d) show the temperature profiles for WTL of 0.75 and 0.40 m, respectively; and (e) and (f)

808 show the electrical conductivity profiles for WTL of 0.75 and $0.40 \mathrm{~m}$, respectively. 

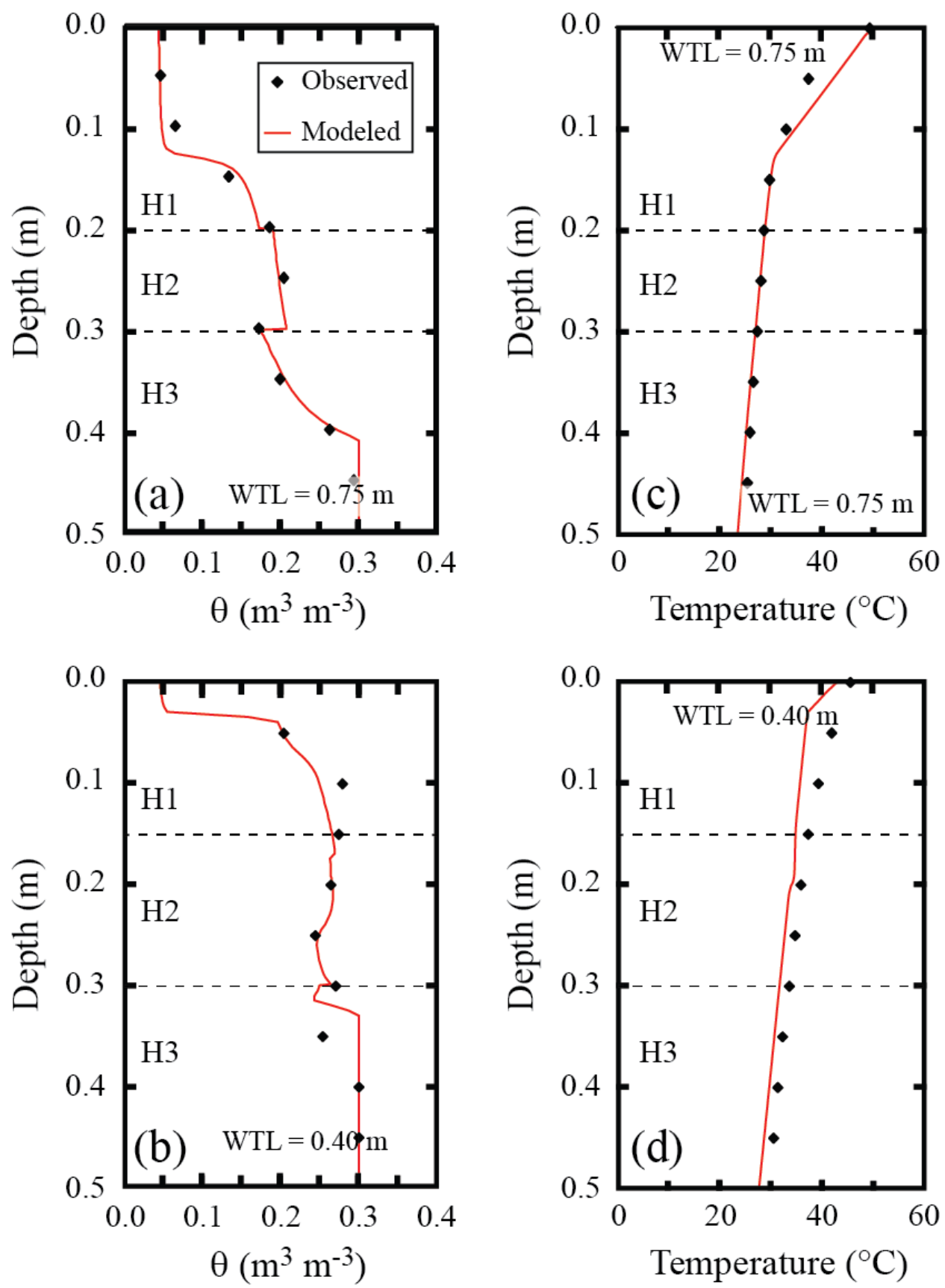

810 Figure 2: Observed and modeled soil water content $(\theta)$ and temperature profiles for different water table levels

811 (WTL), after 20 days of fixing the water table level and assuming the soil stratifies in three horizons (H1, H2, and

$812 \mathrm{H} 3$ ) due to salt transport. (a) and (b) show the soil water content profiles for WTL of 0.75 and $0.40 \mathrm{~m}$, respectively;

813 (c) and (d) show the temperature profiles for WTL of 0.75 and $0.40 \mathrm{~m}$, respectively. 

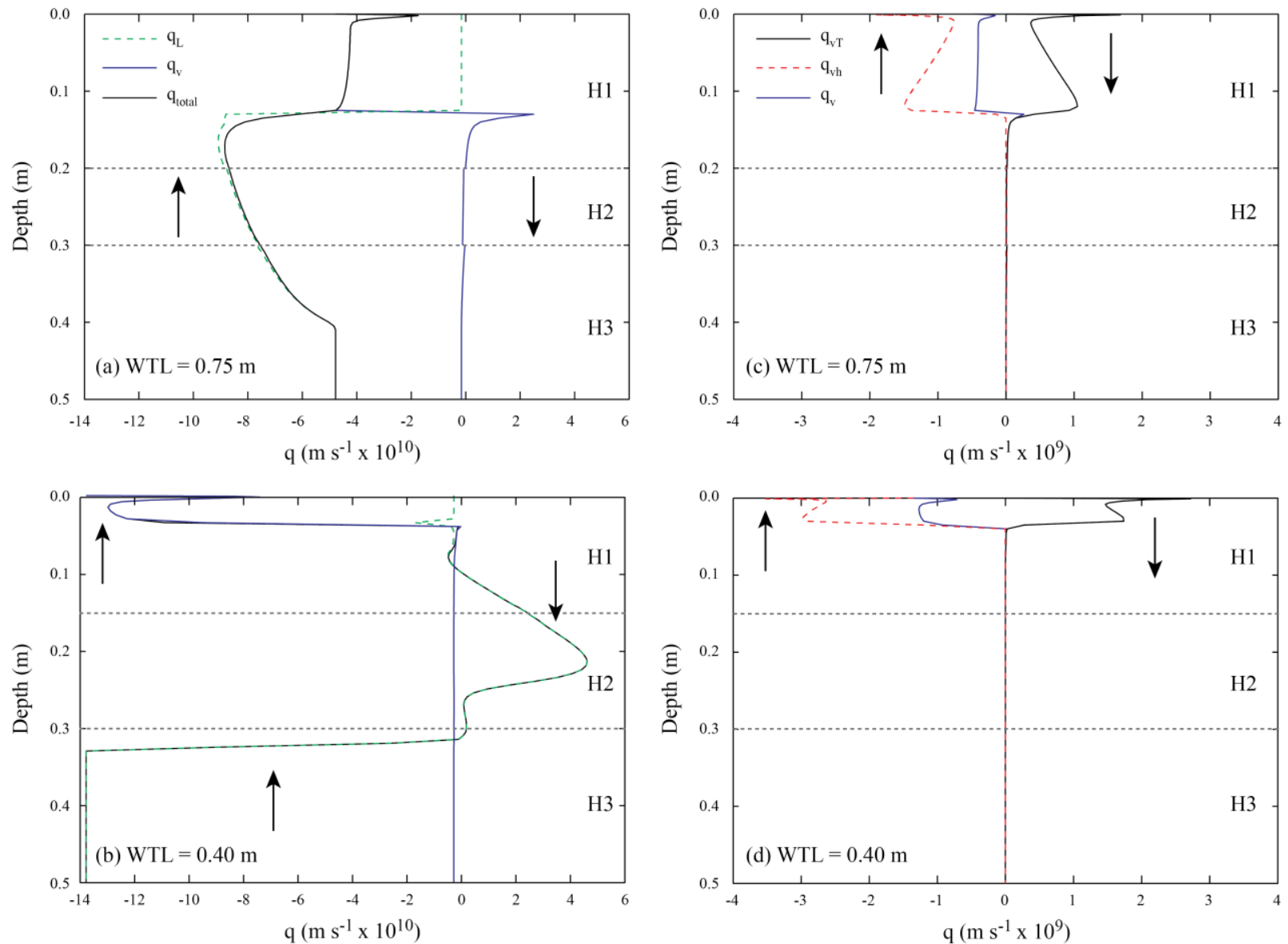

815 Figure 3: Variation of liquid and water vapor flux along the soil profile for different water table levels (WTL). (a)

816 and (b) show the liquid flux $\left(\mathrm{q}_{\mathrm{L}}\right)$, the water vapor flux $\left(\mathrm{q}_{\mathrm{v}}\right)$ and the total water flux $\left(\mathrm{q}_{\text {total }}\right)$ for WTL of 0.75 and 0.40

$817 \mathrm{~m}$, respectively; (c) and (d) show the thermal vapor flux $\left(\mathrm{q}_{\mathrm{vT}}\right)$, the isothermal (due to pressure) vapor flux ( $\left.\mathrm{q}_{\mathrm{vh}}\right)$, and

818 the total vapor flux $\left(\mathrm{q}_{\mathrm{v}}\right)$ for WTL of 0.75 and $0.40 \mathrm{~m}$, respectively. Negative (positive) fluxes correspond to upward 819 (downward) movement. 

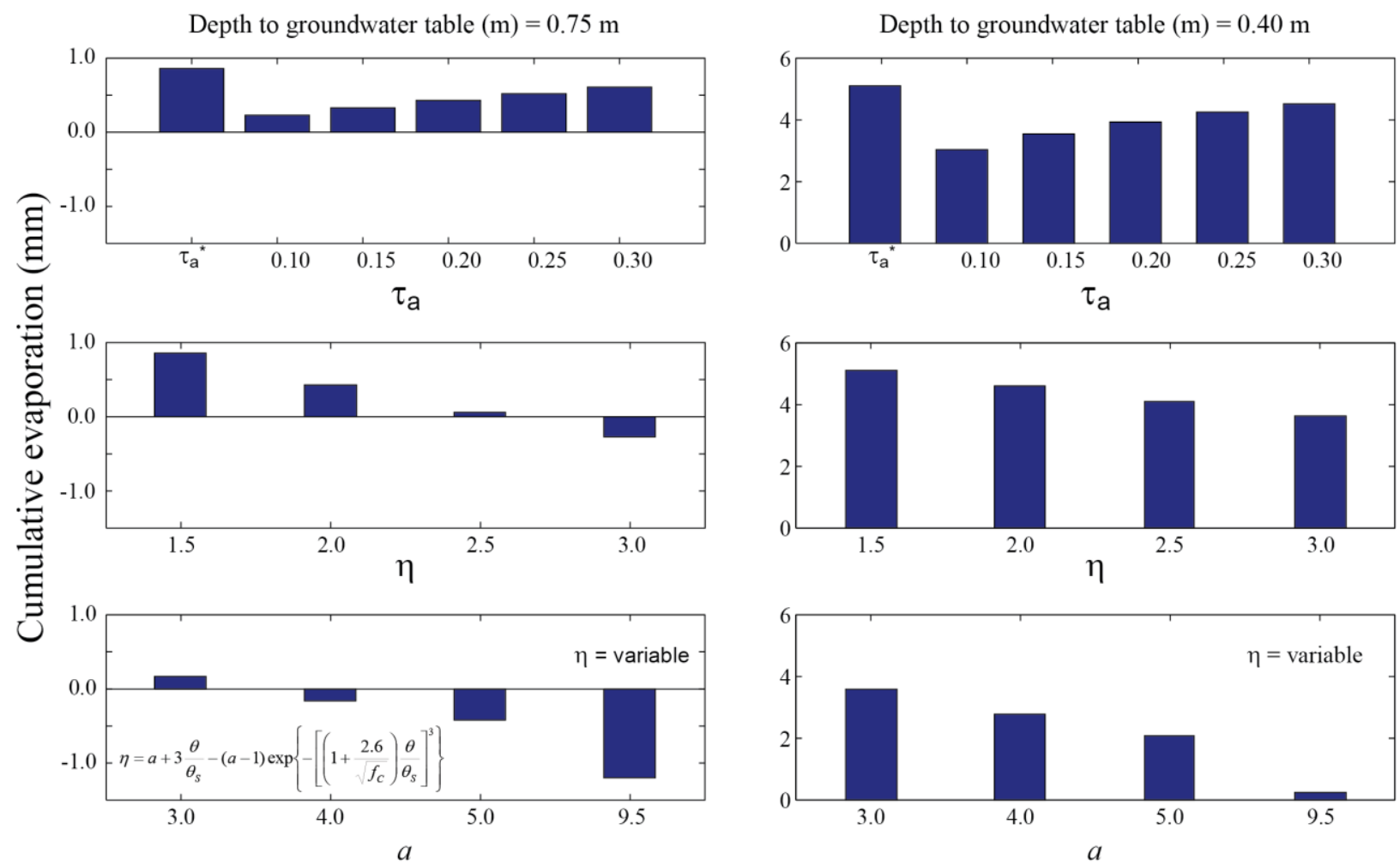

823 Figure 4: Comparison of cumulative evaporation $(\mathrm{mm})$ for different tortuosity values $\left(\tau_{\mathrm{a}}\right)$ and enhancement factors

824 ( $\eta$ ) for the 0.75 and $0.40-\mathrm{m}$ water table levels. $\tau_{\mathrm{a}}{ }^{*}$ was calculated based on equation (15) (Millington and Quirk,

825 1961), and equation (16) was used when $\eta=$ variable (Cass et al., 1984). 
- Experimental data (uniform soil)

- Water retention curve (uniform soil)

- Water retention curve - horizon $\mathrm{H} 2$

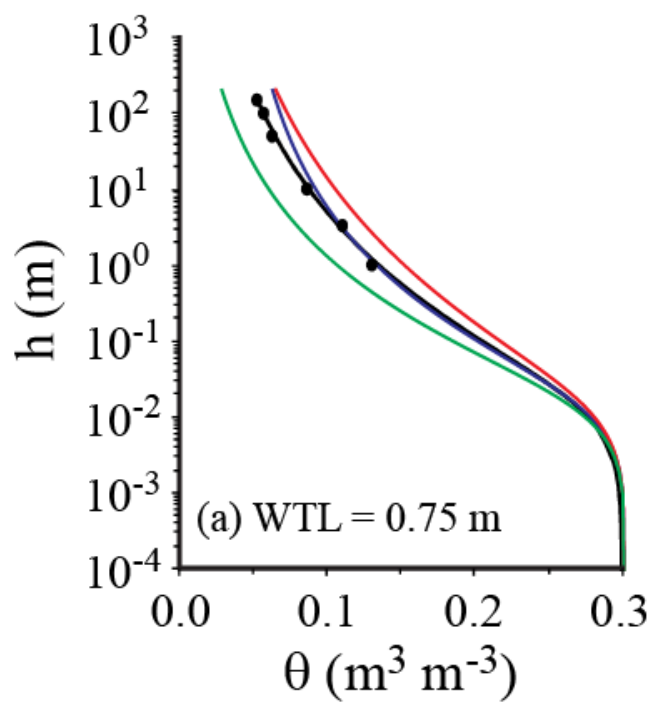

Water retention curve - horizon $\mathrm{H} 1$

Water retention curve - horizon $\mathrm{H} 3$

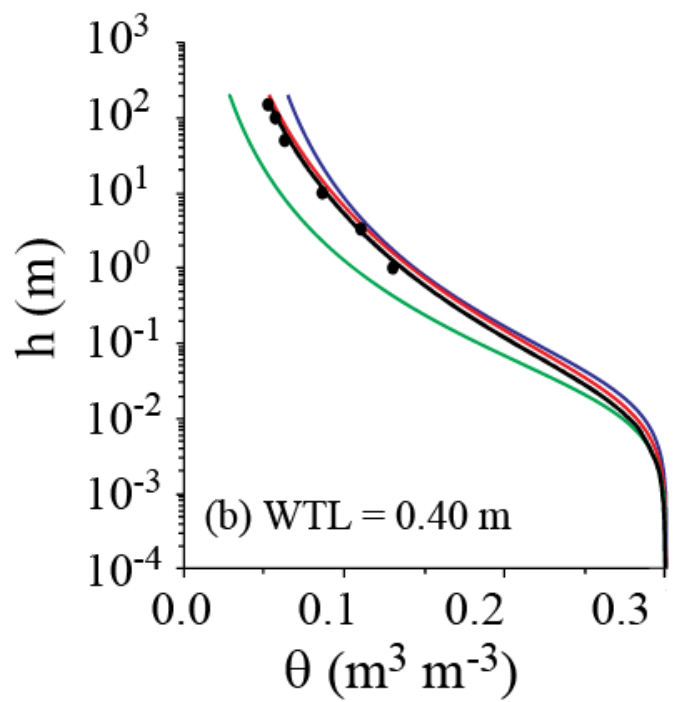



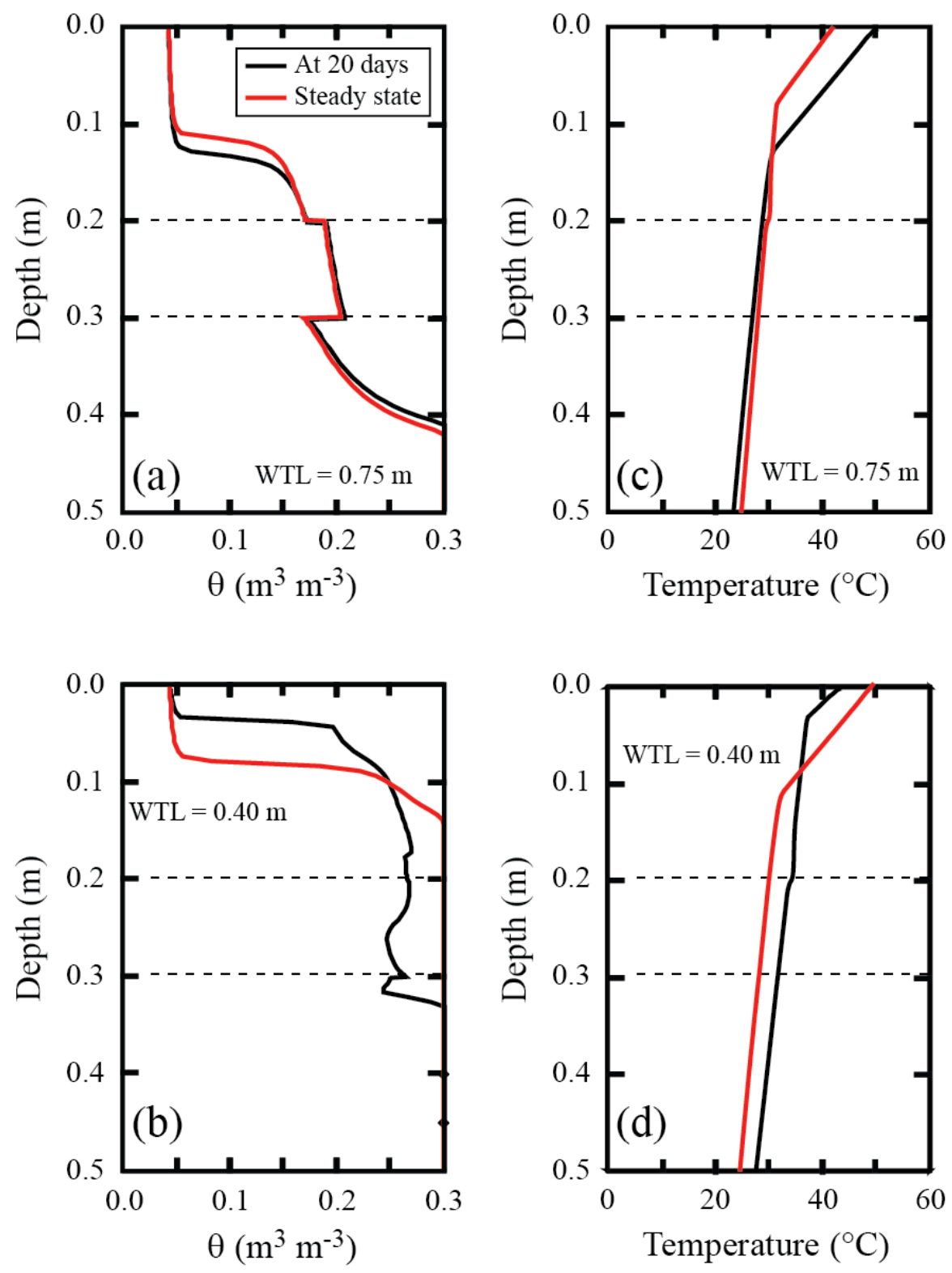

835 Figure 6. Comparison of the soil water content and temperature profiles for the $0.75-\mathrm{m}(\mathrm{a}$ and $\mathrm{c})$ and $0.40-\mathrm{m}(\mathrm{b}$ and

836 d) water table levels (WTL), for the simulation presented in Figure 2 (black) and after steady state was reached (red)

837 when using the bottom boundary conditions equal to the top evaporation flux. 

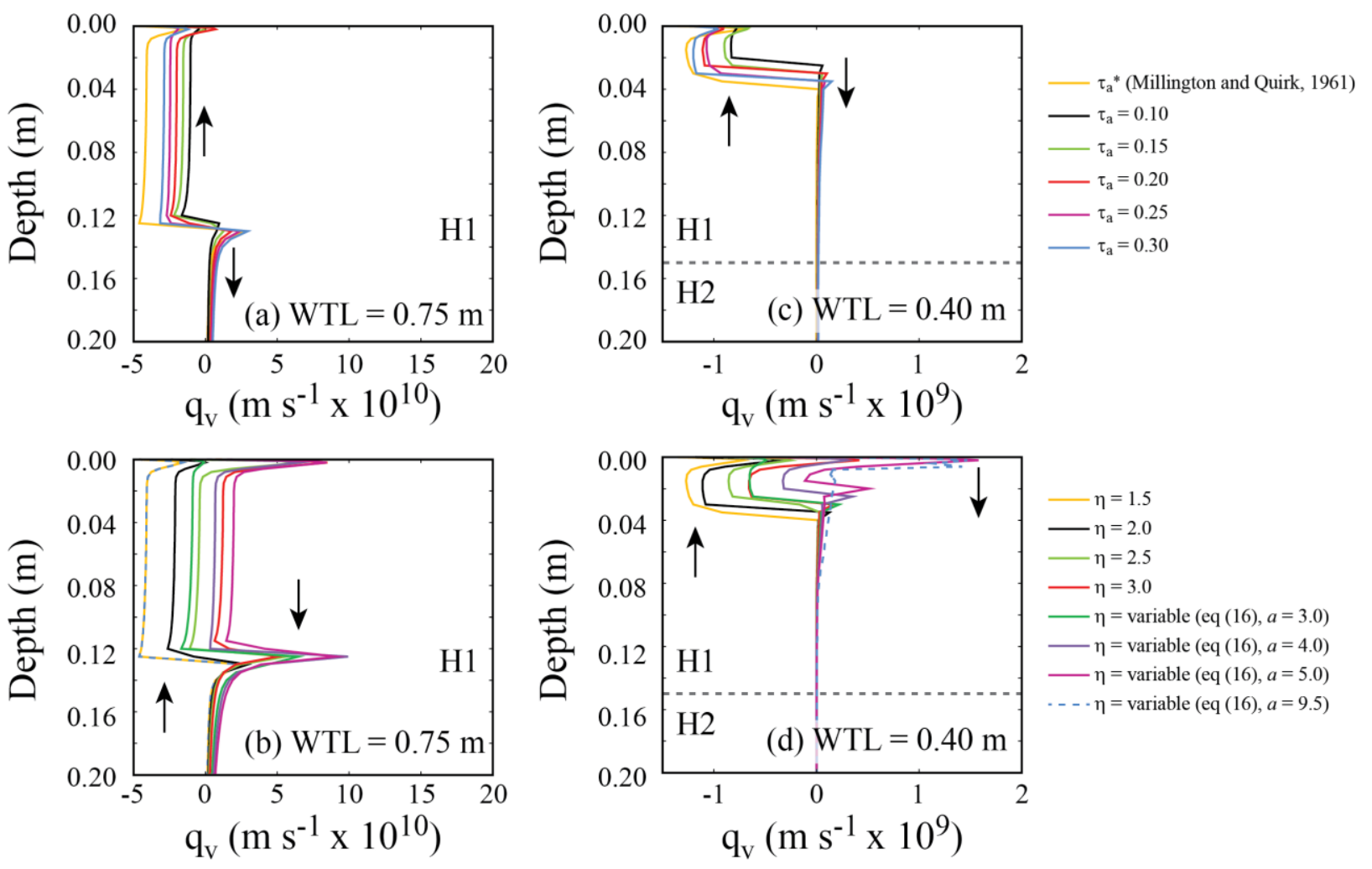

840 Figure 7: Comparison of the water vapor fluxes profiles for the 0.75 and $0.40 \mathrm{~m}$ water table levels (WTL). Results

841 are shown for different tortuosity values, $\tau_{a}$, (a) and (c), and for different enhancement factor values, $\eta$ (b) and (d).

$842 \tau_{\mathrm{a}}{ }^{*}$ was calculated based on equation (15) (Millington and Quirk, 1961), and equation (16) was used when $\eta=$ 843 variable (Cass et al., 1984). Negative (positive) fluxes correspond to upward (downward) movement. 